\title{
A revised L-band radio-brightness sensitivity to extreme winds under tropical cyclones: The 5 year SMOS-Storm database
}

\author{
Reul Nicolas ${ }^{1}$, Chapron Bertrand ${ }^{1}$, Zabolotskikh E. ${ }^{2}$, Donlon C. ${ }^{3,{ }^{*}}$, Quilfen Yves ${ }^{1}$, Guimbard \\ Sebastien ${ }^{1}$, Piolle Jean-Francois ${ }^{1}$
}

${ }^{1}$ Laboratoire d'Océanographie Physique et Spatial (LOPS), Institut Français de Recherche et d'Exploitation de la MER (IFREMER), Centre Bretagne, ZI de la Pointe du Diable, CS 10070, 29280, Plouzané, France

${ }^{2}$ Satellite Oceanography Laboratory, Russian State Hydrometeorological University (RSHU), Malookhtinsky prosp. 98, St. Petersburg 195196, Russia

${ }^{3}$ European Space Agency, ESTEC, Earth Observation Programme Directorate, Mission Science Division, Keplerlaan 1, 2200 AG Noordwijk, The Netherlands

${ }^{*}$ Corresponding author : C. Donlon

nreul@ifremer.fr

\begin{abstract}
:
Five years of SMOS L-band brightness temperature data intercepting a large number of tropical cyclones (TCs) are analyzed. The storm-induced half-power radio-brightness contrast $(\Delta \mathrm{l})$ is defined as the difference between the brightness observed at a specific wind force and that for a smooth water surface with the same physical parameters. $\Delta \mathrm{I}$ can be related to surface wind speed and has been estimated for $\sim 300 \mathrm{TCs}$ that intercept with SMOS measurements. $\Delta \mathrm{l}$, expressed in a common stormcentric coordinate system, shows that mean brightness contrast monotonically increases with increased storm intensity ranging from $\sim 5 \mathrm{~K}$ for strong storms to $\sim 24 \mathrm{~K}$ for the most intense Category $5 \mathrm{TCs}$. A remarkable feature of the $2 \mathrm{D}$ mean $\Delta \mathrm{l}$ fields and their variability is that maxima are systematically found on the right quadrants of the storms in the storm-centered coordinate frame, consistent with the reported asymmetric structure of the wind and wave fields in hurricanes. These results highlight the strong potential of SMOS measurements to improve monitoring of TC intensification and evolution. An improved empirical geophysical model function (GMF) was derived using a large ensemble of colocated SMOS $\Delta \mathrm{l}$, aircraft and $\mathrm{H}^{*} \mathrm{WIND}$ (a multi-measurement analysis) surface wind speed data. The GMF reveals a quadratic relationship between $\Delta \mathrm{l}$ and the surface wind speed at a height of $10 \mathrm{~m}$ (U10). ECMWF and NCEP analysis products and SMOS derived wind speed estimates are compared to a large ensemble of $\mathrm{H}^{*}$ WIND 2D fields. This analysis confirms that the surface wind speed in TCs can effectively be retrieved from SMOS data with an RMS error on the order of $10 \mathrm{kt}$ up to $100 \mathrm{kt}$. SMOS wind speed products above hurricane force $(64 \mathrm{kt})$ are found to be more accurate than those derived from NWP analyses products that systematically underestimate the surface wind speed in these extreme conditions. Using co-located estimates of rain rate, we show that the L-band radio-brightness
\end{abstract}


contrasts could be weakly affected by rain or ice-phase clouds and further work is required to refine the GMF in this context.

\section{Highlights}

- 5 years of SMOS radiometer L-band data intercepts with tropical cyclones are analyzed. The storm-induced brightness contrast $\Delta /$ monotonically increases with their intensity. $\rightarrow$ In average, the brightest $\Delta /$ is found in the right-hand side quadrants of the storms. A quadratic relationship relates $\Delta /$ and the $10 \mathrm{~m}$ height surface wind speed (SWS). SWS can be retrieved from SMOS with an RMS error of $5 \mathrm{~m} / \mathrm{s}$ up to $50 \mathrm{~m} / \mathrm{s}$. 


\section{Introduction}

The measurement of surface wind speed in Tropical Cyclones (TC) is of primary importance for improving storm tracks and intensity forecasts. Unfortunately, obtaining accurate direct or remote measurements at the sea surface level in the extreme conditions of a TC remains a significant challenge (Ulhorn et al., 2007; Powell, 2010, Knaff et al., 2011). Active remote sensing methods of wind measurement saturate in hurricane force winds (e.g., Donelly et al., 1999) and suffer heavily from rain contamination in the TC's eye wall and outer rain band regions (Weissman et al., 2002). In recent years microwave radiometry has played an important role through the successful development and application of the Stepped Frequency Microwave Radiometer (SFMR) that is the National Oceanic and Atmospheric Administration (NOAA)'s primary airborne sensor for estimating surface wind speed in hurricanes (Uhlhorn et al., 2007). The SFMR instrument measures the brightness temperature of the ocean surface using six distinct C-band frequencies, including frequencies which permit the measurement, and correction for, both rain and surface wind speed. Unfortunately, the SFMR is limited by aircraft range in the North Atlantic and Eastern Pacific and there is still no equivalent sensor capability flying in space today. Most available active and passive orbiting sensors operating in the low microwave frequency bands show poor surface wind speed retrieval performances above hurricane force, largely because of the difficulty to precisely separate wind from rain effects (Powell, 2010).

Promising new approaches are nevertheless currently under development based on different sensor technologies. One of these approaches is based on the new capabilities of the Advanced Microwave Scanning Radiometer 2 (AMSR-2) on board the GCOM-W satellite (Zabolotskikh et al., 2015). The method developed by Zabolotskikh et al. (2015) to retrieve sea surface wind speed and rain in tropical cyclones involves the combination of brightness temperature data acquired at the six C-and X-band channels of AMSR-2. Contrarily to the previous AMSR and AMSR-E sensor series, which only operated a single $\sim 6.9 \mathrm{GHz}$ channel, AMSR-2 is now also equipped with an additional C-band channel at $7.3 \mathrm{GHz}$ designed to mitigate for Radio-Frequency Interference (RFI). Using this new channel help to separate the respective contributions from the wind-induced and rain-induced emissivitysignal : this has 
84 been efficiently exploited in the multi-frequency algorithm of Zabolotskikh et al. (2015). Other promising

85 approaches for spaceborne remote sensing of high surface wind speeds include the exploitation of active cross-polarization C-band SAR data (see Horstmann et al., 2013), and L-band GPS bistatic scatterometry

87 (Ruf et al., 2013) following the launch of CYGNSS mission scheduled in 2016.

L-band passive and active measurements from the European Space Agency Soil Moisture and

90 Ocean Salinity (SMOS), the NASA Aquarius-SAC/D and the recently launched Soil Moisture Active 91 Passive (SMAP) missions offer new unique opportunities to complement existing ocean satellite high 92 wind observations in TCs and severe weather. This is because upwelling radiation at $1.4 \mathrm{GHz}$ (L-band) 93 is significantly less affected by rain and atmospheric effects than at higher microwave frequencies (Reul 94 et al., 2012). SMOS provides multi-angular L-band brightness temperature images of the Earth over a $95 \sim 1000 \mathrm{~km}$ swath at about $\sim 43 \mathrm{~km}$ nominal resolution. SMAP performs simultaneous measurement of L96 band brightness temperature, at spatial resolutions of about $40 \mathrm{~km}$ across the entire swath $\sim 1000 \mathrm{~km}$ wide 97 (Entekhabi et al., 2014). Both missions provide data with global coverage in about 3-days due to their 98 large swath. In the context of TC surface wind speed retrieval, the Aquarius sensor is limited because of 99 the low spatial resolution of the three L-band microwave radiometers $(\sim 100 \mathrm{~km})$ and the relatively 100 narrow width of their swaths $(\sim 300 \mathrm{~km}$ when combining all 3 beams $)$, resulting in a global revisit time 101 of only 7 days. While the combination of passive and active L-band measurements is an emerging and 102 promising approach for surface wind speed retrieval in extreme conditions, in this paper, we shall focus 103 only on the brightness temperature signatures of TCs as observed by the SMOS radiometer between $104 \quad 2010-2015$.

105 The first demonstration of SMOS L-band passive microwave data could be used to retrieve 106 meaningful surface wind speed in TCs has been provided in (Reul et al., 2012). The L-band microwave 107 brightness temperature contrast of the sea surface, defined as the difference between the brightness 108 temperature observed at surface level at some wind force and the brightness temperature of the smooth 109 water surface with the same physical parameters (temperature and salinity), were evaluated. The induced 
110 radio-brightness contrasts observed by SMOS as it intercepted storm Igor, a category 4 hurricane, at 111 several stages of its evolution during 11 to 19 September 2010, were co-located and compared to 112 observed and modelled surface wind speed products. From this dataset, a first Geophysical Model

113 Function (GMF) was proposed to describe the relation between the half power L-band radio-brightness 114 contrast of the ocean with the surface wind speed modulus at a height of $10 \mathrm{~m}(\mathrm{U} 10)$. The radio-brightness 115 contrast is defined by:

$116 \Delta \mathrm{I}=\Delta(\mathrm{Th}+\mathrm{Tv}) / 2$

117 where Th and Tv are brightness temperature in horizontal and vertical polarization, respectively. $\Delta \mathrm{I}$ was 118 found to increase quasi-linearly with increasing wind speed with a significant change of sensitivity $119(\partial \Delta I / \partial U)$ from $\sim 0.15 \mathrm{~K} /(\mathrm{kt})$ below hurricane force $(\sim 64 \mathrm{kt})$ to $\sim 0.36 \mathrm{~K} /(\mathrm{kt})$ above. The GMF was used 120 to retrieve surface wind speed from SMOS data over independent storm Igor intercepts. The radii of 34, 12150,64 knots and of the maximum surface wind speeds (that are used to show the bi-dimensional 122 evolution of the surface wind speed structure), were shown to be consistent with the NOAA/Geophysical 123 Fluid Dynamic Laboratory (GFDL) hurricane model solutions and the H*WIND analyses (Powell et al., 124 1998) from the Hurricane Research Division (HRD) of the Atlantic Oceanographic and Meteorological 125 Laboratory. The authors concluded that the surface wind speed modulus over $\sim 40 \mathrm{~km}$ pixels can be 126 retrieved with a root mean square error of $\sim 10 \mathrm{kt}(\sim 5 \mathrm{~m} / \mathrm{s})$.

Heavy rain and ice clouds in the atmosphere have a potential impact on the L-band radio128 brightness contrasts, and sea state effects remain rather uncertain and could also be sources of larger 129 amplitude local errors on the retrieved surface wind speed. These effects were not considered in the GMF 130 of Reul et al. (2012). The effect of rain and the atmosphere on radio emission from the sea surface is 131 certainly weaker at L-band than it is at the higher frequencies (Reul et al., 2012). Atmospheric 132 contributions are dominated by absorption and emission due to oxygen at L-band and can be corrected 133 with negligible errors (Yueh et al., 2001) with respect the magnitude of the wind-induced surface radio134 brightness contrasts. The absorption due to rain of upwelling radiations is also two order of magnitude 135 larger at C-band frequencies compared to those at L-band (see Fig2b in Reul et al., 2012). Nevertheless, 
136 high wind regions in TC are very often associated with extreme rain rates and the atmosphere around the

137 eye walls is very often associated with high concentration of several hydrometeor species such as cloud 138 water, ice, snow, and graupel (Houze et al., 1976). Small ice particles exist between the eye wall and 139 outer rain bands, and graupel particles are collocated with the radius of maximum tangential wind (Houze 140 et al., 1992). Hurricanes are usually glaciated everywhere above the $-5^{\circ} \mathrm{C}$ level and the stratiform cloud 141 areas are dominated by snowflakes (aggregates) at these levels (Black and Hallett., 1986). The impact on 142 L-band emissions of ice phase clouds, of the concomitant high rain rate around a TC eye wall and rain 143 bands remains largely unknown. In Reul et al. (2012) an attempt to quantitatively evaluate the rain impact 144 at a given wind speed was performed using co-located rain rate measurements from various microwave 145 sensors by classifying the estimated L-band radio-contrasts in both rain-free and rainy conditions during 146 four intercepts of storm Igor. Based on the limited data used and previous radiative transfer simulations, 147 it was concluded that rain has a negligible impact on the L-band brightness temperature at high winds, 148 except in very high-extreme rain rates. In those conditions, the maximum rain impact can induce a wind 149 speed retrieval error of up to $\sim 12 \mathrm{kt}(\sim 6 \mathrm{~m} / \mathrm{s})$. To reduce these effects further requires a better knowledge 150 of the rain and ice impacts over a statistically significant number of storm samples from which a new 151 GMF can be derived.

152 The brightness temperature of the ocean is strongly dependent on the foam coverage due to 153 whitecap and streaks induced by wave breaking and wind tearing of the wave crest (Nordberg et al. 1971, 154 Ross and Cardone 1974, Webster et al. 1976, Holthuijsen et al., 2012) but also on the distribution of foam 155 formation thickness (Newell and Zakharov, 1992; Reul and Chapron, 2003, Anguelova and Gaiser 2012; 156 Golbraikh and Shtemler, 2016). Recent observations from Holthuijsen et al., 2012 suggest that the 157 whitecap coverage is not increasing at hurricane wind force and above to reach a constant value of about $1584 \%$. The "whitening" of the sea surface observed above $64 \mathrm{kt}$ is therefore dominated by the growth of 159 streak coverage. Whether it is the increasing coverage of these streaks, or the increasing thickness of the 160 whitecaps, or a combination of both that explain the quasi-linear growth of the radio-brightness at L161 band remains an open question. Both characteristics can be related to wind speed, but surface wave 
162 breaking and streak generation are also strongly dependent on wave growth, wave-wave and wave163 current interaction, water depth and the changing (turning) direction of winds. The physics of wave 164 breaking generation processes within hurricanes is complicated by the rapidly turning winds that generate 165 cross-seas and higher sea state in the forward right-hand quadrant of storms in the northern hemisphere 166 (and in the left-hand quadrant for the southern hemisphere). The velocity of forward movement of the 167 storm, the maximum wind velocity, and radius of maximum wind for a given storm as well as the duration 168 of wind action with respect group velocity of waves, are key parameters known to play an important role 169 in determining both the magnitude and spatial distribution of the waves generated within storm quadrants 170 (Young, 2003; MacAfee and Bowyer, 2005, Kudryavtsev et al., 2015). The wave field is thus more 171 asymmetric than the corresponding wind field, mainly due to the "extended fetch" which exists to the 172 right (left in the Southern hemisphere) of a translating hurricane due to relative wind/wave motions. It 173 is worth noting that the effects of wave-current interaction on surface foam formation may also be 174 important for hurricanes in some areas, e.g. in the U.S., due to the strong influence of either the Gulf 175 Stream (Western Atlantic) or the Loop Current (Gulf of Mexico). Yet, the impact on the radio-brightness 176 contrast at L-band of wave and wave breaking development and variability in storm quadrants is still 177 poorly known. Thus, algorithms for wind speed retrieval from L-band microwave radiometry must be 178 developed that are sensitive to these effects using a statistically significant number of storm samples from 179 which a new GMF can be derived.

In this paper, we present results of a study conducted to extend the initial work of Reul et al.

181 (2012) and gain further insight into wind, rain, and sea state effects on L-band radio brightness contrasts.

182 We systematically produced L-band SMOS radio-contrasts and high wind speed retrievals and generated 183 a global database of SMOS intercepts with all TC events that developed over the global ocean during the 184 period January 2010 to April 2015. Data and processing are described in the first section. We then show 185 several examples of the SMOS radio-contrast signal and retrieved winds for various representative 186 storms. In part three, we analyse the statistical properties of the L-band brightness temperature contrasts 187 as function of storm sectors and storm intensity to illustrate the capability of L-band passive microwave 
188 data to provide a metric for intensity change in TCs. We then validate SMOS retrieved winds based on 189 the first GMF derived by Reul et al., 2012 using different surface wind speed products. The quality of 190 SMOS wind is then assessed and compared to European Center Medium-range Weather Forecasts 191 (ECMWF) and Numerical Centers for Environmental Prediction (NCEP) wind speed products in the 192 range 0-100 kt. Based on these co-located data sets, a refined new GMF function is proposed. Finally, 193 we discuss the limitations and characteristics associated with the new L-band observations (potential 194 effects of rain and sea state and others) and the enhanced storm tracking capability that are now possible 195 using merged SMOS-AMSR2 and SMAP data.

\section{Data and Methods}

\section{$197 \quad 2.1 \quad$ SMOS data and processing}

198 SMOS brightness temperature $\left(\mathrm{T}_{\mathrm{B}}\right)$ images are formed through Fourier synthesis from the cross 199 correlations between simultaneous signals obtained from pairs of antenna elements. For this study, we used the SMOS Level 1B V620 products, generated by the ESA/SMOS Data Processing Ground Segment (DPGS). The SMOS Level-1B (L1B) product is the output of the image reconstruction of the 202 observations and comprises the Fourier component of the $\mathrm{T}_{\mathrm{B}}$ in the antenna polarization reference frame. 203 Level-1B corresponds to one temporal measurement, i.e., the whole field of view, one integration time, 204 and is often called a 'snapshot'. $\mathrm{T}_{\mathrm{B}}$ images are then obtained by applying an inverse Fast Fourier 205 Transform (IFFT) to the Level 1B $\mathrm{T}_{\mathrm{B}}$ Fourier coefficients using a Blackman spatial filter as described by Anterrieu et al. (2002). The reconstructed $\mathrm{T}_{\mathrm{B}}$ product at the top of the atmosphere is geo-located in an 207 equal-area grid system (ISEA 4H9 - Icosahedral Snyder Equal Area projection) with an oversampled 208 spatial resolution of about $\sim 15 \mathrm{~km}$. We consider here $T_{B}$ data reconstructed in the extended field of view 209 (FOV) domain of the antenna for which the swath width is approximately $1200 \mathrm{~km}$ (see Font et al., 2010,

210 Figure 6). The actual spatial resolution of the reconstructed $\mathrm{T}_{\mathrm{B}}$ data varies within the FOV from $\sim 32 \mathrm{~km}$ 211 at boresight to about $\sim 80 \mathrm{~km}$ at the edges of the swath (43 km on average over the field of view). The 212 earth-view incidence angle ranges from nadir to about $60^{\circ}$ and the radiometric accuracy from $2.6 \mathrm{~K}$ at 213 boresight to about $4-5 \mathrm{~K}$ on the swath edges. As the satellite moves, multiple observations of the same 
214 pixel at different incidence angles are obtained from successive snapshots. Earth grid point with less than

2155 multi-angular observations (typically encountered at the extreme border of the swath) are removed.

The L-band $\mathrm{T}_{\mathrm{B}}$ measured by a downward looking radiometer such as that on board SMOS are

217 significantly influenced by a number of radiation sources (Yueh et al., 2001; Font et al., 2010). The most

218 important sources of L-band brightness over the ocean are: (1) perfectly flat surface emission (with order

219 of magnitude $\sim 100 \pm 4$ K due to Sea Surface Salinity (SSS) and Sea Surface Temperature (SST) variability

220 impact); (2) atmospheric emission (on the order of $\sim 5 \mathrm{~K}$ including reflected down-welling and upwelling

221 emissions); (3) scattered cosmic background and galactic radiation incident at the surface (order of

222 magnitude $\sim 10 \mathrm{~K}$ ); and (4) excess emission associated with the wind-driven surface roughness and

223 breaking-wave generated foam (order of magnitude $10-30 \mathrm{~K}$ depending on the wind strength). All but

224 one of these contributions can be estimated using data together with the SMOS Level 2 radiative transfer

225 forward model of scene brightness (Zine et al., 2008) to generate individual residual sources $\Delta \mathrm{T}_{\mathrm{B}}$ of

226 brightness contrast. Using this approach, we removed all but the rough and foam-surface emission

227 contributions from the SMOS measurements. In the SMOS forward model (Zine et al., 2008), the

228 evaluation of atmospheric contributions do not account for potential rain impact, which is hereafter

229 neglected. The resulting data set is then used to reveal the impact of surface roughness and foam changes

230 on the SMOS $\mathrm{Tb}$ in $\mathrm{TC}$ conditions. Additional geophysical auxiliary data required to evaluate the

231 different forward model contributions are obtained operationally at the SMOS measurement time and

232 location by the DPGS using products from ECMWF.

To estimate the flat sea surface emission contribution, we used the ECMWF/OSTIA Sea Surface

234 Temperature daily night time products (Donlon et al. 2012) and we estimated the sea surface salinity

235 (SSS) using SMOS SSS data themselves for the week preceding the passage of the storms. For this study,

236 we used the Centre Aval de Traitement des Données SMOS (CATDS, www.catds.fr) Expertise Center-

237 Ocean Salinity SMOS SSS (IFREMER V02) Level 3 products (Reul and Ifremer CATDS-CECOS Team,

238 2011). Data were first processed to provide a level 3 daily gridded SSS field at a spatial resolution of

$2390.25^{\circ} \times 0.25^{\circ}$ for the complete year. Composite weekly products were then generated for each storm 
240 using a 7-day running mean and a $0.5^{\circ}$ spatial window. The SSS was further bi-linearly interpolated to

$24115 \mathrm{~km}$ resolution to evaluate the brightness contrast $\Delta \mathrm{T}_{\mathrm{B}}$ induced by salinity and temperature changes 242 alone. Reul et al. (2012) estimated that SSS errors on the order of $\sim 0.5$ pratical salinity scale (the accuracy 243 of weekly CATDS products in the tropics) will translate into maximum wind speed bias of $\sim 1 \mathrm{~m} / \mathrm{s}$. 244 Nevertheless, large tropical river plumes (Amazon, Mississipi) can exhibit significant SSS variability on 245 time scales less than a week (eg. tidal effects, currents, sudden increase in the river discharge): using SSS 246 fields estimated from preceeding weekly data in such high variability areas may be an additional source 247 of local error on the retrieved wind speed.

248 Polarization mixing (Faraday rotation), due to the electromagnetic wave propagation through the 249 ionosphere in the presence of the geomagnetic field (Skou and Hoffman-Bang, 2005) is an additional 250 source of L-band Tb modification as measured from space. It can be either modelled from the knowledge 251 of the ionospheric Total Electron Content (TEC) and magnetic field or avoided by using the first Stokes 252 parameter:

$253 \quad \mathrm{I}=\mathrm{T}_{\mathrm{H}}+\mathrm{T}_{\mathrm{V}}$

254 which is invariant by rotation. We choose such alternative approach and estimate both the first Stokes 255 surface roughness and foam-induced Tb residual using:

$257 \Delta \mathrm{I}=\Delta \mathrm{T}_{\mathrm{H}}+\Delta \mathrm{T}_{\mathrm{V}}$

258

$260-5.0 \mathrm{~K}$ for a single snapshot measurement as function of the position of the pixel within the swath), we 261 average the SMOS multi-angular measurements at a given location to estimate an 'incidence-angle 262 averaged' first Stokes brightness temperature residual generated by surface roughness and foam: 263

$264 \overline{\Delta I}=\frac{1}{\theta_{\max }-\theta_{\min }} \int_{\theta_{\min }}^{\theta_{\max }} \Delta I(\theta) d \theta$ 
266 where $\theta$ is the earth incidence angle and $\left[\theta_{\min }, \theta_{\max }\right] \approx\left[10^{\circ}, 60^{\circ}\right]$.

267 The different spatial resolution within the SMOS swath (a function of incidence angle) increases the 268 uncertainty in the estimated surface $\overline{\Delta I}$. A weighted average of the $\Delta I$ (designed to minimise the 269 contribution from the largest pixels) would potentially reduce errors associated with variable spatial 270 resolution. However, a simple averaging procedure was chosen to systematically and consistently reduce 271 the relatively high instrument instantaneous radiometric noise. The noise-reduction approach through

272 incidence-angle averaging is necessary in the context of SMOS because of the low signal-to-noise ratio 273 for a single angle measurement. The approach is justified by the fact that a small incidence-angle 274 dependence of the foam impact is expected from radiative transfer models of foam emissivity at L-band 275 in the range $0^{\circ}-50^{\circ}$ (Reul and Chapron, 2003; Camps et al., 2005; Yueh et al., 2010), a characteristic 276 which was confirmed in the observations over hurricane Igor (Reul et al., 2012). In this paper we will 277 consider the half total power:

$279 \quad \frac{\Delta \bar{I}}{2}=\Delta\left(T_{H}+T_{V}\right) / 2$

281 and for clarity, we shall drop the overbar notation. Unless specified, $\Delta I$ will therefore always refer to the 282 incidence angle-averaged half-power quantity. Surface wind speed modulus is finally retrieved from $\Delta \mathrm{I}$ 283 data using the bi-linear GMF proposed in Reul et al. 2012, hereafter referred to as GMF1.

\section{$284 \quad 2.2 \quad$ Storm Tracks and Intensity}

285 Tropical cyclone "best track" data (Jarvinen et al. 1984) were obtained from the WMO International Best 286 Track Archive for Climate Stewardship (IBTrACS, Knapp et al. 2010). We used the best track archive 287 dataset version v03r06 available at NOAA National Climatic Data Center 288 (https://www.ncdc.noaa.gov/ibtracs/). The database includes 6-hourly storm center track location and 289 maximum one-minute sustained wind speed information. We used the "source" datasets in the Best track 290 data that combines information from the most reliable tropical cyclone data centres. At the time this work 
291 was conducted, the IBTrACS tracks database only included few storms in 2014 and none in 2015. For 292 these two years, we completed the storm track database using data from the Joint Typhoon Warning 293 Center (JTWC) and National Hurricane Center (NHC).

294 Best-track data are a subjectively-smoothed representation of a tropical cyclone's location and intensity 295 over its lifetime and generally will not reflect the erratic motion implied by connecting individual center 296 fix positions. In the present work, the position of the storm centre at the time of SMOS acquisition was 297 determined by default using a linear interpolation in time of the best track data. Uncertainties on the 298 estimate of the storm centre location at SMOS acquisition time nevertheless result from the combined 299 errors of the smoothed representation of the best-track data and from the use of a linear time-interpolation 300 method. The NOAA/Hurricane Research division proposes alternative wind center fixes and interpolated 301 tracks using a series of spline curves with varying degrees of curvature (Willoughby and Chelmow, 302 1982). However, such interpolated track data are only available for those North Atlantic and East Pacific 303 hurricanes in which aircraft reconnaissance flights were performed. As we processed a large number of 304 storms in other basins without aircraft data, microwave $85 \mathrm{GHz}$ data from SSMI/IS 15-16-17-18, TMI, 305 WindSAT, AMSR-E and AMSR-2 were used for complementary checks. The latter data are available 306 from the Morphed Integrated Microwave Imagery (MIMIC-TC) database provided by the Cooperative 307 Institute for Meteorological Satellite Studies Space Science (CIMSS). Adjustments were performed if a 308 visual inspection revealed discrepancy between the best tracks interpolated storm-center location, the 85 $309 \mathrm{GHz}$ and the SMOS fields (e.g., cases when the centre is very easily detectable on SMOS data by visual 310 inspection but displaced from best track or $85 \mathrm{GHz}$ 's estimates). The bearing of the storm center main 311 motion at SMOS acquisition time was also estimated from the time interpolated 6-hourly best-track data.

\section{$312 \quad 2.3 \quad$ Surface wind speed products}

313 SMOS retrieved winds are compared with a set of alternative surface wind speed datasets including

314 Numerical Weather products and retrieved surface winds from either the SFMR operated aboard the 
315 NOAA and Air Force aircrafts or H*WIND analyses (Powell et al., 1998). Both data are available from 316 the Hurricane Research Division (HRD) of the Atlantic Oceanographic and Meteorological Laboratory.

317 The SFMR was specifically developed to measure hurricane-force ocean surface winds and is typically 318 mounted on aircraft that makes reconnaissance flights with radial passes through the center of TCs. The 319 SFMR measures the nadir brightness temperatures between 4.5 and $7.2 \mathrm{GHz}$ and the data available are 320 processed with a 10-second running mean to derive surface wind speeds and rain rates using dedicated 321 GMF (Uhlhorn et al., 2007) at a resolution of $\sim 3 \mathrm{~km}$. Based on a comparison of SFMR to GPS dropsonde 322 wind speed measurements, an error of approximately $4 \mathrm{~m} / \mathrm{s}$ in TC winds between 10 and $70 \mathrm{~m} / \mathrm{s}$ is 323 expected (Uhlhorn et al., 2007).

324 To validate and re-analyse the SMOS GMF, we also used $\mathrm{H}^{*}$ WIND two-dimensional surface wind 325 analysis products (Powell et al., 1998). The $\mathrm{H}^{*}$ WIND analysis uses a combination of all available surface 326 and near surface wind observations collected over a period of several hours from multiple platforms (i.e., 327 SFMR wind speeds, GPS dropwindsondes, tail Doppler radar, geostationary operational environmental 328 satellite (GOES) cloud track winds, surface ships and buoy data as well as satellite observations (such as 329 QuikSCAT, WindSat and ASCAT), etc.). The analysis procedure adjusts each data set to a common 330 elevation and exposure and creates a $6 \mathrm{~km}$ resolution surface wind field for each TC in a "storm-centric" 331 moving coordinate system. The wind speed represents the one-minute sustained wind velocity at $10-\mathrm{m}$ 332 height reference. These objectively analyzed wind products are used routinely as guidance for operational 333 TC forecast and advisory products, including the determination of wind radii (e.g., radius of maximum 334 wind and at 34, 50, and $64 \mathrm{kt}$ winds) by hurricane forecasters at the National Hurricane Center and the 335 Central Pacific Hurricane Center. The H*WIND accuracy is highly dependent on the quality of the 336 dataset and data coverage used as input. Although it is imperfect, it is the best 2D surface truth currently 337 available. Note that these fields are only freely available now until 2013, post 2013 data will be made 338 available for non-commercial research purposes (M. Powell, pers. Comm.). 
341 according to the time difference. This results in adjusted flight tracks such that SFMR and $\mathrm{H}^{*}$ WIND 342 measurements have the same location with respect to the centre of the storm at the time of the SMOS 343 acquisition as they actually had when they were recorded. This adjustment does not consider any storm 344 rotation. The storm's movement is derived from the best track information from IBTrACS. We 345 considered all SFMR and $\mathrm{H}^{*}$ WIND observations available within \pm 12 hours from SMOS data. The two 346 closest $\mathrm{H}^{*}$ WIND wind fields in time before and after a SMOS overpass of a given TC available \pm 12 347 hours from SMOS were linearly interpolated to the SMOS acquisition time. To assess the performance 348 of SMOS winds, comparisons were performed with both SFMR and H*WIND products kept at their 349 original spatial resolution, respectively 3 and $6 \mathrm{~km}$, but smoothed to match the SMOS average spatial 350 resolution by using a running spatial 2D Gaussian windows (Brinkman and Bodschwinna, 2003) with 351 standard deviation equal to $43 \mathrm{~km}$.

Note that Hurricane surface winds are strongly dependent on the averaging time attributed to the 353 wind observations, the roughness of the underlying surface, and height of the wind measurements above 354 the sea surface. The NHC best track maximum sustained surface wind is defined as the maximum one355 minute wind observed at a height of $10 \mathrm{~m}$. Here, all the other wind products are also referred to a $10 \mathrm{~m}$ 356 height. The $\mathrm{H}^{*}$ WIND averaging time is also one minute, so that the SMOS retrieved wind speeds derived 357 using the GMF of Reul et al. (2012) are calibrated based on a one-minute averaging period. However, 358 the SMOS spatial resolution is much coarser and a better approach, more consistent with the spatial 359 resolution of SMOS, is to use the maximum 10-minute wind as used by most of world's operational 360 centers outside of the USA. Therefore, all wind speed value derived based on a 1 minute averaging period 361 were adjusted to a 10-minute standard: 10 -minute averaged wind speed are $\sim 7 \%$ smaller than 1 -minute 362 averages (Harper et al., 2008).

363 The performance of SMOS winds in storms with respect to numerical weather forecast fields from 364 ECMWF and NCEP operational models are assessed using ECMWF 10-m equivalent neutral wind data 365 that are also used as auxiliary information in the SMOS operational SSS Level 2 processor. Six-hourly 
366 GFS NCEP wind speed products were also co-located in space and linearly interpolated in time with

367 SMOS acquisition and compared to paired SMOS/H*WIND data.

\section{$2.4 \quad$ Rain data}

369 We use satellite rainfall rate estimates from the CMORPH products (CPC MORPHing technique) that 370 include global precipitation analyses at high spatial $(\sim 8 \mathrm{~km})$ and temporal resolution ( $\sim 3$ hourly). The 371 approach (Joyce et al., 2004) uses precipitation estimates derived exclusively from low earth orbit 372 satellite microwave observations, and whose features are advected via spatial propagation information 373 that is obtained from geostationary satellite infrared (IR) data. At present NOAA incorporate 374 precipitation estimates derived from the following satellites instruments: DMSP 13, 14 and 15 (SSM/I), 375 NOAA-15, 16, 17 and 18 (AMSU-B), Aqua (AMSR-E), TRMM (TMI) and GPM (DPR and GMI). IR 376 data are used as a means to propagate the microwave-derived precipitation features during periods when 377 microwave data are not available to a given location. Propagation vector matrices are produced by 378 computing spatial lag correlations on successive images of geostationary satellite IR that are then used 379 to propagate the microwave derived precipitation estimates. This process governs the movement of the 380 precipitation features only. At a given location, the shape and intensity of the precipitation features in the 381 intervening half hour periods between microwave scans are determined by performing a time-weighting 382 interpolation between microwave-derived features that have been propagated forward in time from the 383 previous microwave observation and those that have been propagated backward in time from the 384 following microwave scan. NOAA refer to this latter step as "morphing" of the features. CMORPH 385 estimates cover a global belt $\left(-180^{\circ} \mathrm{W}\right.$ to $\left.180^{\circ} \mathrm{E}\right)$ extending from $60^{\circ} \mathrm{S}$ to $60^{\circ} \mathrm{N}$ latitude and are available 386 at ftp://ftp.cpc.ncep.noaa.gov/precip/CMORPH_V1.0/RAW/

387 With regard to spatial resolution, although the precipitation estimates are available on a grid with a 388 spacing of $8 \mathrm{~km}$ (at the equator), the resolution of the individual satellite-derived estimates is coarser 389 than that - more on the order of $12 \times 15 \mathrm{~km}$. The finer "resolution" is obtained via interpolation. Similarly 390 to the wind speed products, we estimated the rain rate on the SMOS $15 \mathrm{~km}$ resolution grid by averaging 
391 the CMORPH data using a 2D Gaussian window of $43 \mathrm{~km}$ width. The two closest CMORPH fields in 392 time (before and after a SMOS overpass of a given storm) are linearly interpolated to the SMOS 393 acquisition time.

\section{SMOS STORM Database}

\section{$395 \quad$ 3.1 General Characteristics of the SMOS Storm database and analysis subset}

396 A database of SMOS interceptions with Tropical Cyclones has been generated for the satellite data 397 archive period from January 2010 to April 2015 called the "SMOS-STORM database". SMOS intercepts 398 for all TCs within the database were determined by selecting SMOS swaths that intercepted the storm 399 tracks. For each swath, the SMOS L1B data were processed to estimate the residual half-power first 400 Stokes radio-brightness contrasts, $\triangle \mathrm{I}[\mathrm{K}]$, (Eq. 5) at surface level on a $15 \mathrm{~km}$ grid. The SMOS retrieved 401 2D wind speed modulus fields based on the first GMF (Reul et al., 2012), hereafter referred to as GMF1, 402 were first computed and co-located with a suite of auxiliary geophysical information (ECMWF, NCEP

403 wind and SST, SSS, etc.). The intercept swaths were then classified by year, basin and storm name. A 404 sub-ensemble of about 300 SMOS swath intercepts with Tropical storms and cyclones was then selected 405 based on how well the swaths intercepted each storms centre (the storm centre and its spatial domain 406 within a radius of $\sim 100-200 \mathrm{~km}$ had to be well observed by SMOS). The selection was also based on the 407 quality of SMOS data within each swath (minimum RFI contaminations and undetectable residual 408 uncorrected solar effects...). Only the data of the highest quality possible were selected to physically 409 interpret the L-band contrasts in storms and then invert the data into geophysical parameters (wind, wave, 410 rain, etc..).

411 The distribution of $\Delta \mathrm{I}[\mathrm{K}]$ associated with that sub ensemble of intercepts is shown in Fig. 1. As shown,

412 we selected storms in almost all the active basins of the world oceans showing the variability of brightness 413 temperature contrast distribution in each basin. 

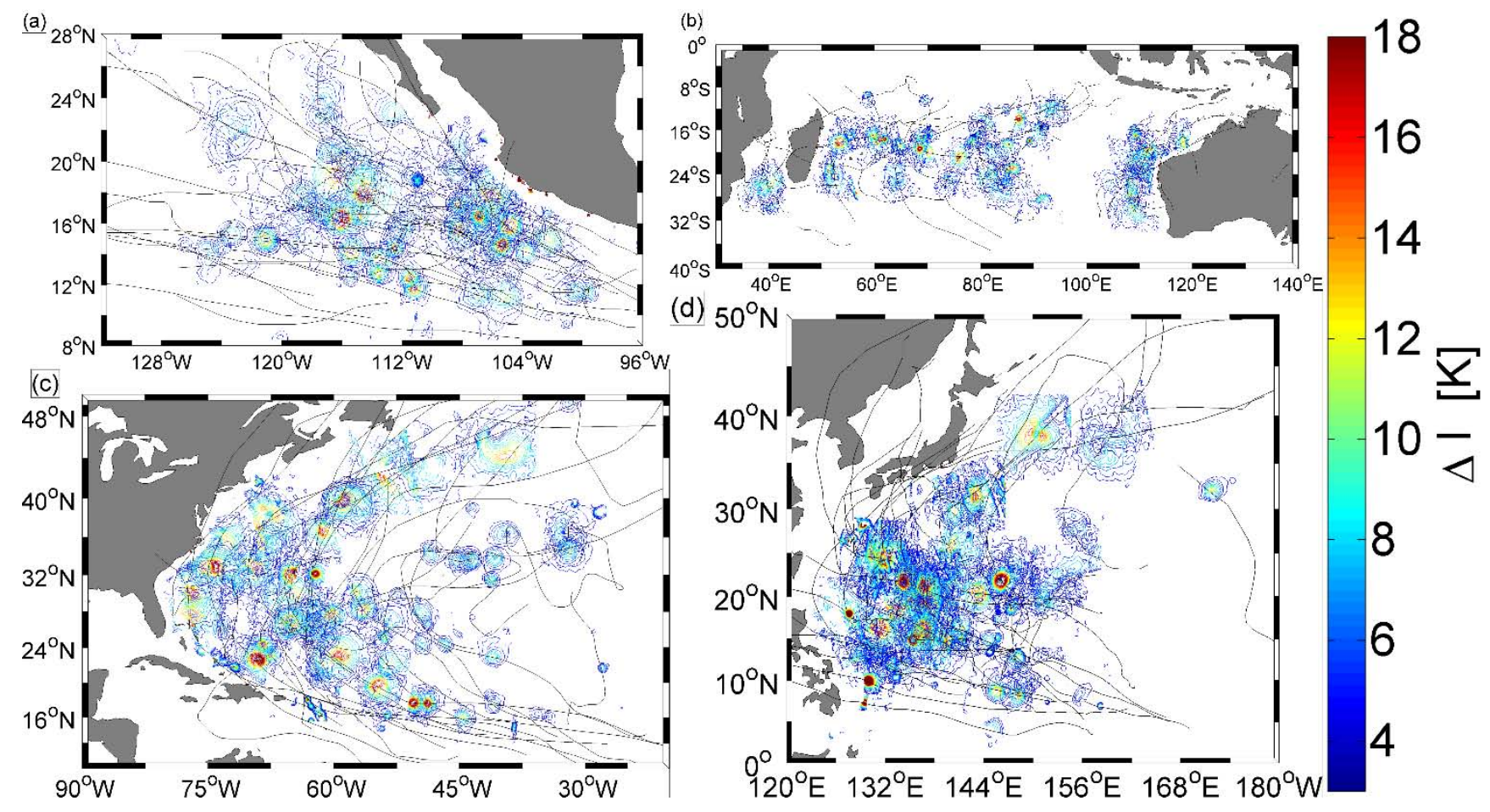

Fig. 1. Contours of storm-surface induced brightness temperature contrasts $\Delta I[K]$ estimated from SMOS L-band data for an ensemble of storms in the Eastern Tropical Pacific (a), Southern Indian Ocean (b), North Atlantic (c), and Western Pacific ocean (d) during 2010-2015. The black thin curves indicate the storm tracks. The coloured contours indicate the amplitude of the storm-induced radio-brightness temperature contrasts $[\mathrm{K}]$.

Individual examples of SMOS $\triangle \mathrm{I}$ for different intensity storms ranging from tropical storms to category 4 on the Saffir-Simpson Wind Scale (SSWS) are shown in Fig. 2. As shown, the shape, magnitude and spatial extent of the storm-induced L-band brightness temperature contrasts demonstrate significant variability around the storm centers. Large asymmetries in the distribution of $\Delta \mathrm{I}$ around the storm centers are particularly evident for the tropical storms and category 1-2 TCs. The magnitude of the maximum $\triangle \mathrm{I}$ varies from $<12 \mathrm{~K}$ for Tropical storms to well above $18 \mathrm{~K}$ for Category 4 cyclones on different sides of the storm tracks. Significant drops of $\Delta \mathrm{I}$ in the storm center region, known to be associated with light winds and low rain, are sometimes visible but are not systematically observed, particularly for those storms showing radii of significant $\Delta \mathrm{I}$ contrasts that are similar or less than the SMOS average spatial resolution $(\sim 43 \mathrm{~km})$. Further classification of SMOS storm intercepts in which the best track one-minute maximum sustained wind speed at the time of SMOS acquisitions was matched 
4344 and 3 category 5 events.

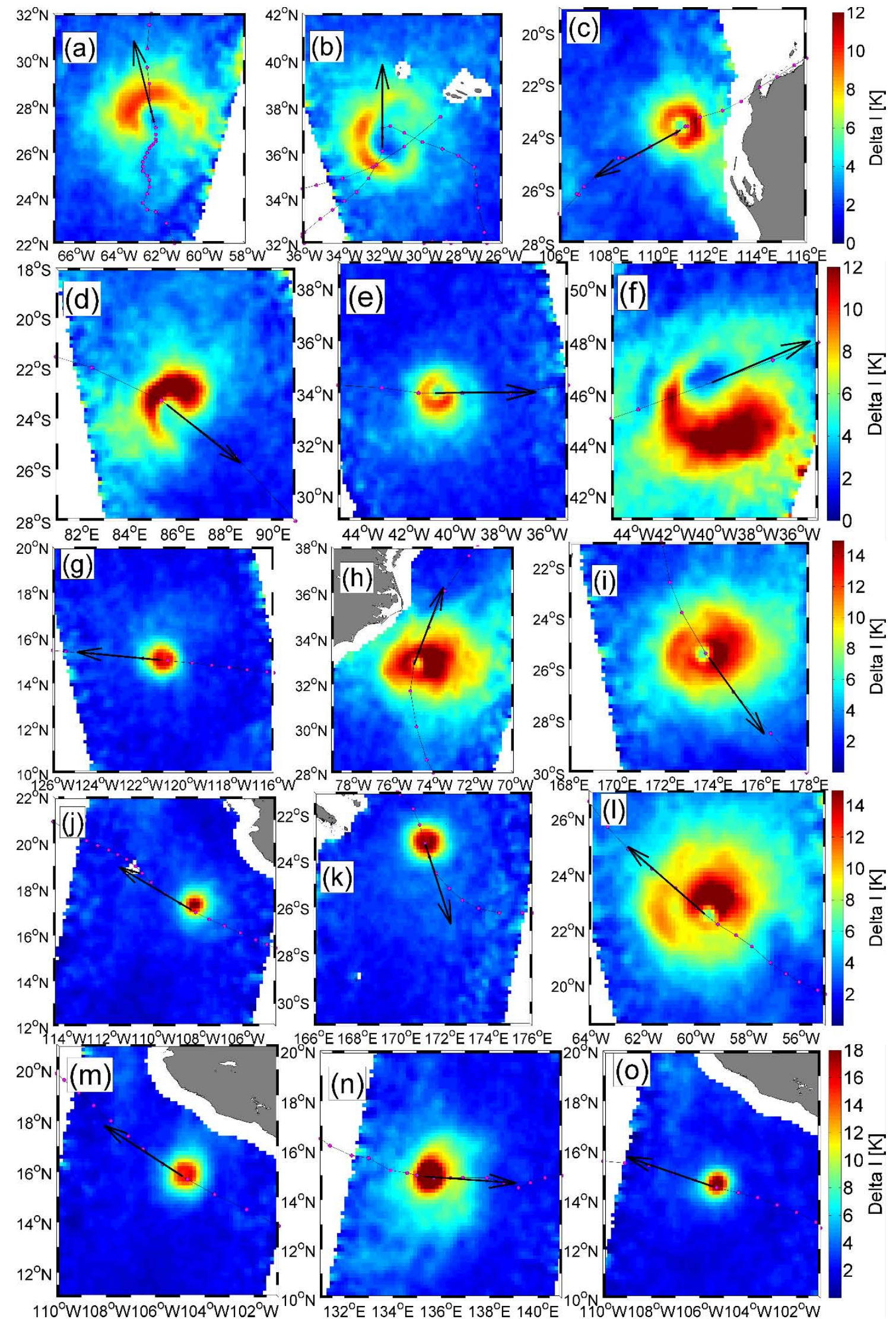

436 Figure 2: Examples of SMOS L-band radio-brightness temperature contrasts $\Delta \mathrm{I}[\mathrm{K}]$ measured for tropical Storms 
TCs (j,k,l; $\left.96 \leq \mathrm{U}_{10} \leq 113 \mathrm{kts}\right)$ and category $4 \mathrm{TCs}$ (m,n,o: $\left.114 \leq \mathrm{U}_{10} \leq 135 \mathrm{kts}\right)$ on the SSWS. Note that the color-scale range is $0-12 \mathrm{~K}$ for TS and category $1,0-15 \mathrm{~K}$ for category 2 to 3 and $0-18 \mathrm{~K}$ for category 4 on the SSWS. Each panel represent a domain of about $1000 \mathrm{~km}$ width centred on the TC eye. The pink dotted curves show the storm

\subsection{Statistical characteristics of the L-band brightness contrasts as function of storm intensity} 444 and sectors

\subsubsection{Transformation of $\Delta \mathrm{I}$ into Storm-centric and common propagation direction frame}

To estimate the 'average' statistical properties of $\Delta \mathrm{I}$ and its relationship to storm intensity and storm sector, each SMOS intercept with a storm was processed as follows:

1) The storm center was determined at the time of SMOS acquisition by interpolating linearly in space and time the storm track 6-hourly IBTracks data to the SMOS acquisition time,

Microwave $85 \mathrm{GHz}$ data from SSMI15-16-17-18, TMI or AMSRE that were acquired within less than \pm 1 hour from SMOS intercepts were then used to check the determination of the storm center locations estimated from the best-track data. If $85 \mathrm{GHz}$ images were available within less than \pm half an hour from SMOS, the location of the storm centre was determined using these data. Otherwise, the storm centre location was bi-linearly interpolated in space and time from the two closest $85 \mathrm{GHz}$ observations acquired just before and after SMOS acquisition. A visual check was further performed to check consistency between SMOS-derived storm centre location, besttrack location, and $85 \mathrm{GHz}$ interpolated locations. In case of a significant mismatch, the centre determined from the $85 \mathrm{GHz}$ data was used by default. Fig. 3 shows an example for a SMOS intercept with hurricane Jova on 10 October 2011 as it developed in the eastern Pacific into a Category 3 storm before it landed in western Mexican coasts. SMOS intercepted the storm at 12:32 Z. The best-track linearly-interpolated storm centre location at that hour (Fig. 3, top left) is found at $\sim\left[16.35^{\circ} \mathrm{N}, 106.8^{\circ} \mathrm{W}\right]$ which is $\sim 0.3^{\circ}$ north of the observed maximum in SMOS brightness temperature contrast $\left[16.05^{\circ} \mathrm{N}, 106.78^{\circ} \mathrm{W}\right]$. If the best-track determined centre location is assumed to be the actual storm centre, then the SMOS $\Delta \mathrm{I}$ distribution, as observed, would be 

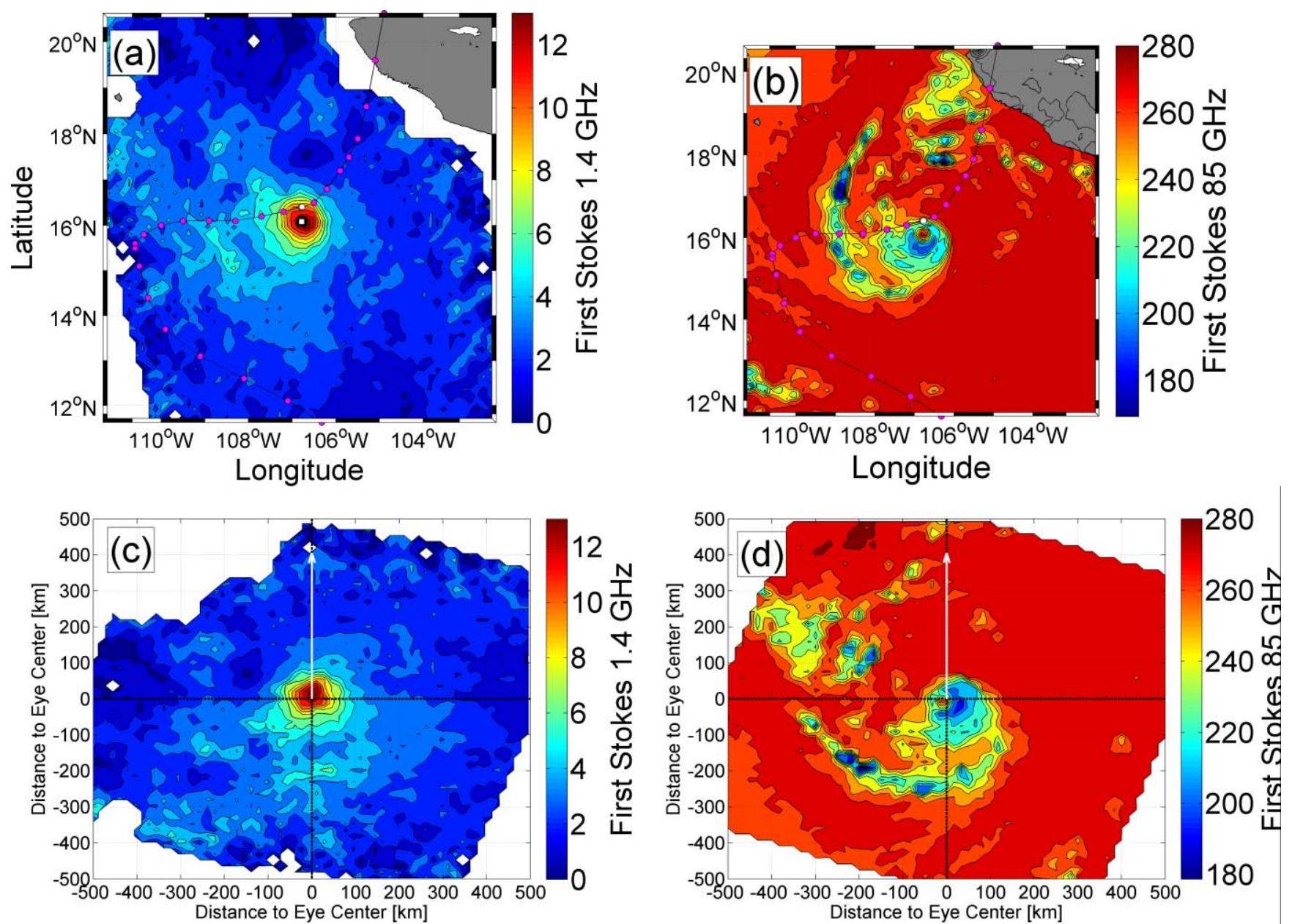

475

476

477

478

479

480

481

482 different storm sectors.

Figure 3: (a): SMOS $\Delta \mathrm{I}$ estimated over Category $3 \mathrm{TC}$ Jova at $12: 32 \mathrm{Z}$ on 10 October 2011. The pink dotted curve shows the Best Track of Jova; the white filled dot and square indicate the eye location estimated by linear interpolation of the Best Track data at SMOS acquisition time and from the closest $85 \mathrm{GHz}$ acquisition. In this case, the latter is obtained from SSMIS/17 imagery at 12:59 Z (b). (c) and (d): same fields as top panels but provided in a storm-centric frame of $1000 \mathrm{~km}^{2}$ and rotated with respect the storm heading "North Up" that is shown as a white arrow. 
483 For convenience, we arbitrarily choose to rotate all $\Delta \mathrm{I}$ distributions to a "northern-hemisphere" common 484 coordinate system display geometry (see example for Jova in Fig. 3, which was actually heading towards 485 the northeast at the SMOS acquisition time). Using the storm centre locations estimated at the SMOS 486 acquisition times all $\Delta \mathrm{I}$ data were further re-gridded at $15 \mathrm{~km}$ spatial resolution on a storm-centric 487 coordinate system with west-east and north-south axes spanning a spatial domain of $500 \mathrm{~km}$ on each side 488 of the storm centre. The heading of the storm translation motion was then estimated from the best-track 489 interpolated data at the SMOS acquisition time and the $\Delta \mathrm{I}$ fields were rotated to align all storm translation 490 directions to a common axis. Note that the fields were reflected around that axis (i.e. to flip the wind 491 fields in left/right direction) for the southern-hemisphere storms to account for the different veering wind 492 directions in both hemispheres. SMOS winds were not adjusted to account for the storm translation speed 493 but only rotated based on the motion direction.

\subsubsection{Statistical distributions of $\Delta \mathrm{I}$ as function of storm intensity and sectors}

We compute the $2 \mathrm{D}$ distributions of the mean and standard deviation of L-band $\Delta \mathrm{I}$ as function of the 497 different Saffir-Simpson TC categories for all storms in our database and plot the result in Fig. 4 using 498 storm-centric coordinates (ie. all storms have been consistently rotated to point "North Up"). The mean 499 distributions of $\Delta \mathrm{I}$ coherently increase with the increasing TC intensity. The radii within which the 500 brightest $\Delta \mathrm{I}$ values are found for each category reduces as the storm intensity increases, consistent with 501 the reported evolution of the highest surface wind distribution in TCs (Holland, 1980, Chavas et al., 502 2015). A remarkable feature of the mean $\Delta \mathrm{I}$ fields is that the maxima are systematically found on the 503 right-hand side quadrant of the storms. This is also consistent with the reported asymmetric structure of 504 the wind and wave fields in TC where the maximum in wind speed and sea surface heights occur in the right-hand quadrant of the storm (in the northern-hemisphere) because of the relative wind created by a 506 translating storm (Uhlhorn et al. 2014; Rogers and Uhlhorn, 2008; Molinari and Skubis, 1985). Except 507 for the lower intensity tropical storm case, the standard deviation (STD) of $\Delta \mathrm{I}$ fields also reflect similar 508 characteristics to the mean field. For TC categories 1-5, the STD shows a quasi-annular distribution 
510 and local maxima in the right-hand quadrant of the storms.
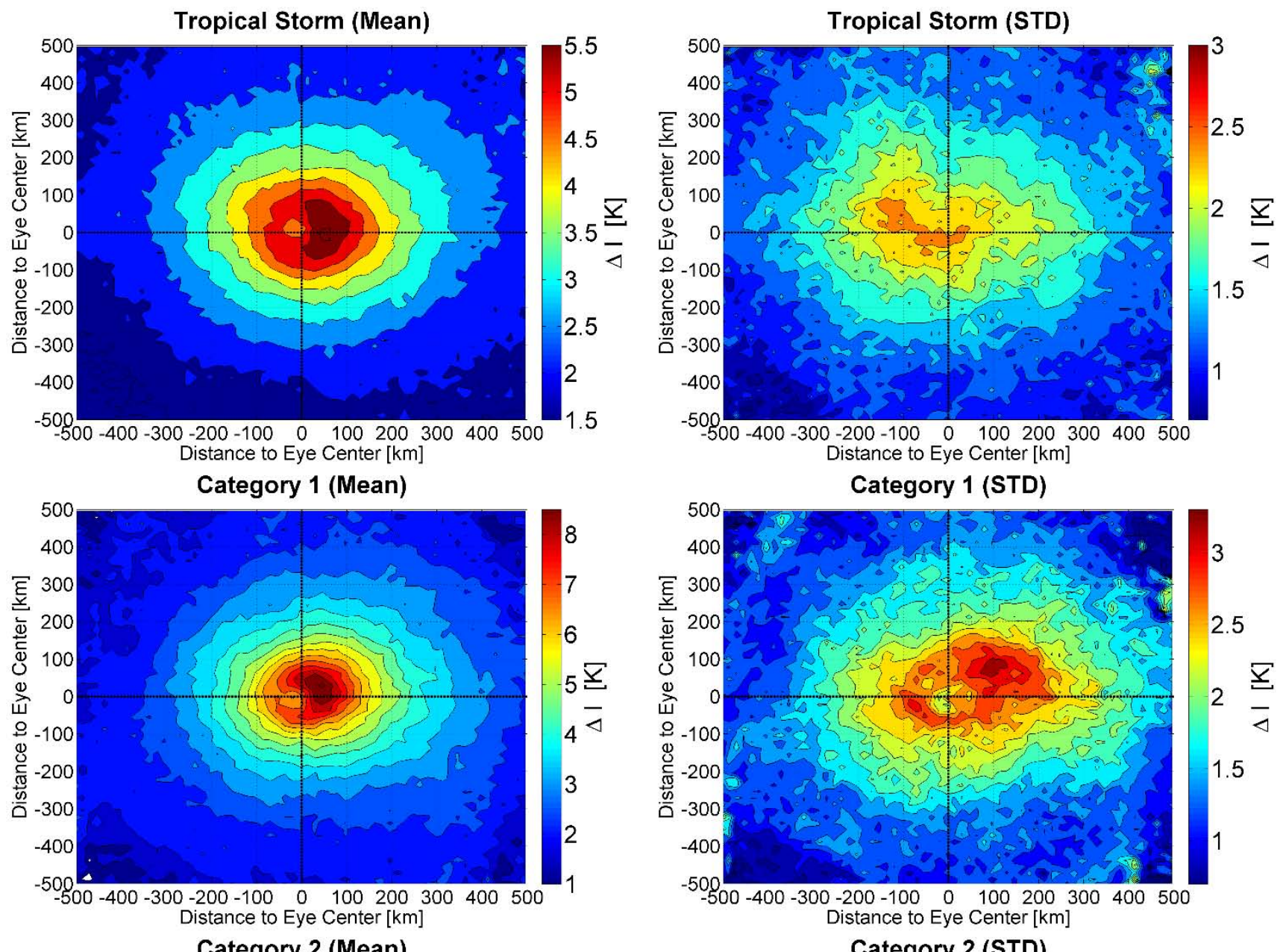

Category 1 (STD)

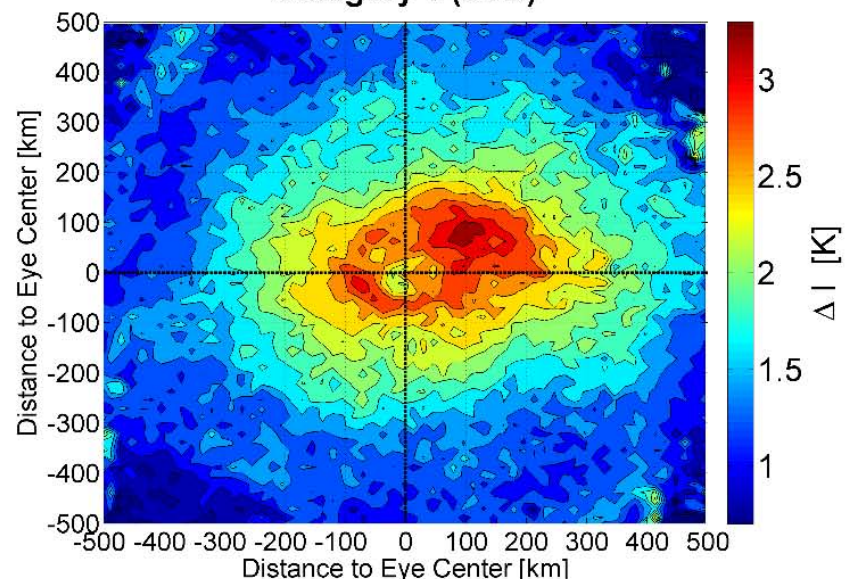

Category 2 (STD)
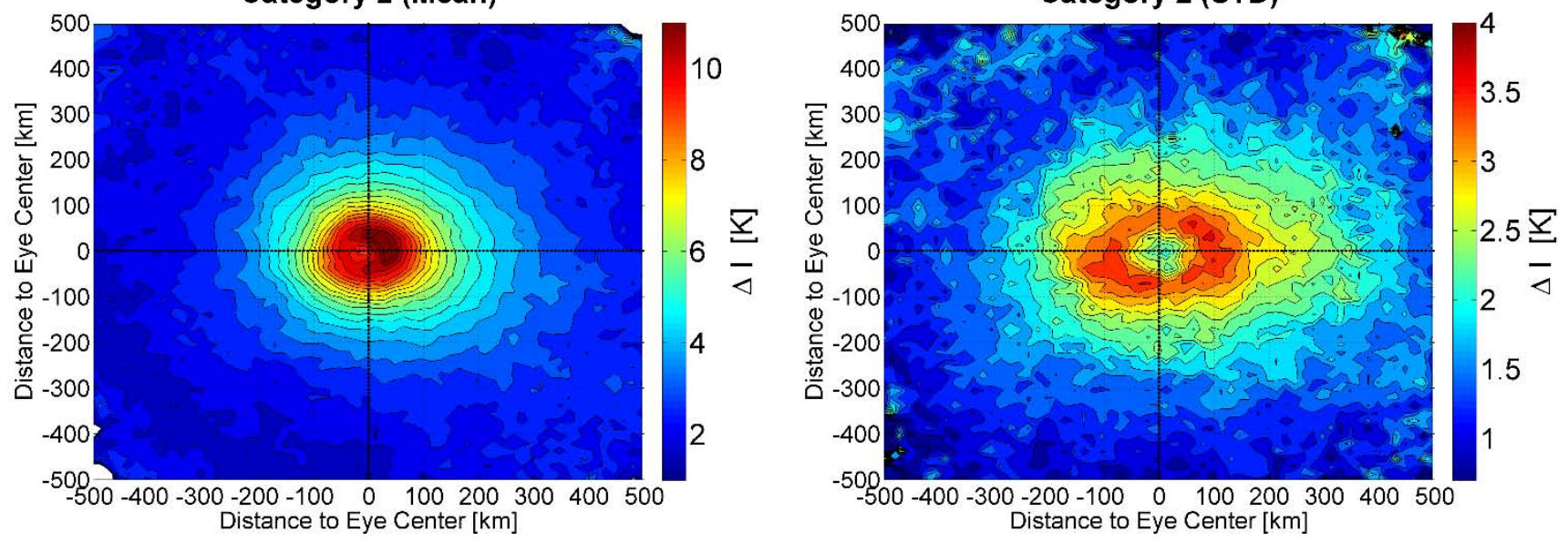

512 (see legend and rest of the figure next page)

513

514 

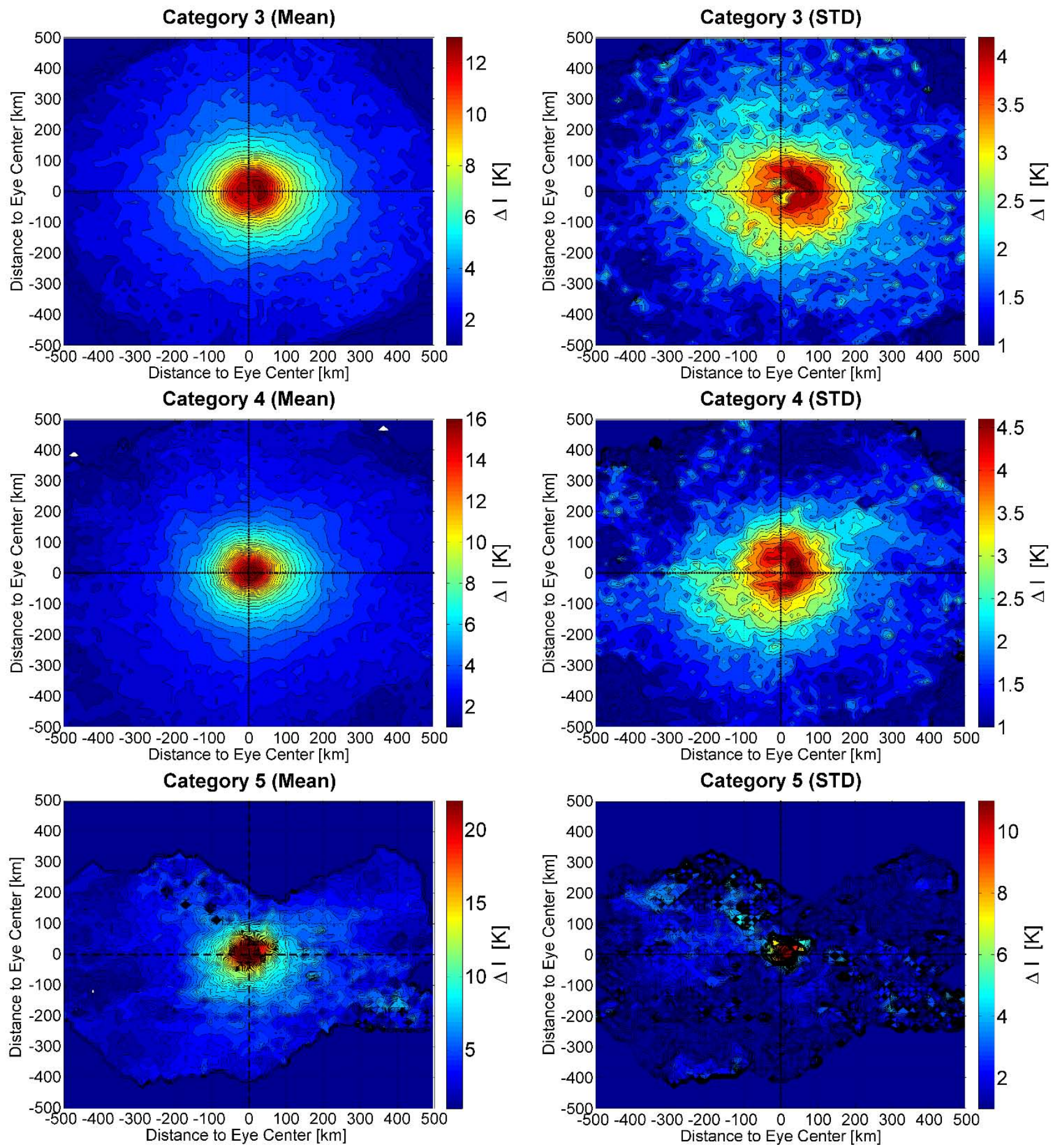

Fig. 4. Storm centric contours of the mean (left panels) and standard deviation (right panels) of the L-band radio brightness half power contrast $(\Delta \mathrm{I}[\mathrm{K}])$ as function of storm sector and intensity. The wind intensity is ranging from tropical storms (top panels, $35 \leq \mathrm{U}_{10} \leq 63 \mathrm{kts}$ ), Category $1 \mathrm{TCs}$ (second panels from top, $64 \leq \mathrm{U}_{10} \leq 82 \mathrm{kts}$ ), Category 2 TCs ( $3^{\text {rd }}$ panels from top, $\left.83 \leq \mathrm{U}_{10} \leq 95 \mathrm{kts}\right)$, Category $3 \mathrm{TCs}\left(4^{\text {th }}\right.$ panels from top, $\left.96 \leq \mathrm{U}_{10} \leq 113 \mathrm{kts}\right)$, Category $4 \mathrm{TCs}\left(5^{\text {th }}\right.$ panels from top, $114 \leq \mathrm{U}_{10} \leq 135 \mathrm{kts}$ ) and Category 5 (bottom panels, $\left.\mathrm{U}_{10}>135 \mathrm{kts}\right)$. Contours range from 1 to $28 \mathrm{~K}$ in steps of $0.5 \mathrm{~K}$ for the mean and from 0 to $10 \mathrm{~K}$ in steps of $0.2 \mathrm{~K}$ for the standard deviation. Note that the colour scale range is changing from top to bottom panels.

Fig. 5 highlights the storm quadrant and intensity dependencies of SMOS $\Delta \mathrm{I}$ for all tropical cyclones in our database. The mean brightness contrast is clearly seen to monotonically increase with 
528 storm intensity within a $\sim 200 \mathrm{~km}$ radius from the storm centre. The mean $\Delta \mathrm{I}$ amplitude ranges from about $5295 \mathrm{~K}$ for tropical storms up to $\sim 24 \mathrm{~K}$ for the most intense category 5 cyclones. There is no evidence of $\Delta \mathrm{I}$ 530 saturation and the brightness increases between TC categories by $\sim 3-4 \mathrm{~K}$. The step change from Category 5314 to Category 5 is more significant $(\sim 8 \mathrm{~K})$ but this result is not robust given that only 3 Category 5 events 532 were intercepted by SMOS. There is evidence of a right-hand-side asymmetry and the maxima of $\Delta \mathrm{I}$ is 533 always found in the north-east and south-east quadrants. The typically calm inner-core wind structure is 534 difficult for SMOS to resolve when the radii of maximum wind is less than $\sim 43 \mathrm{~km}$ (the mean spatial 535 resolution of the SMOS data) and is most noticeable for the intense wind conditions (category 4 and 536 above) where the radial structure of the TC is typically compressed.
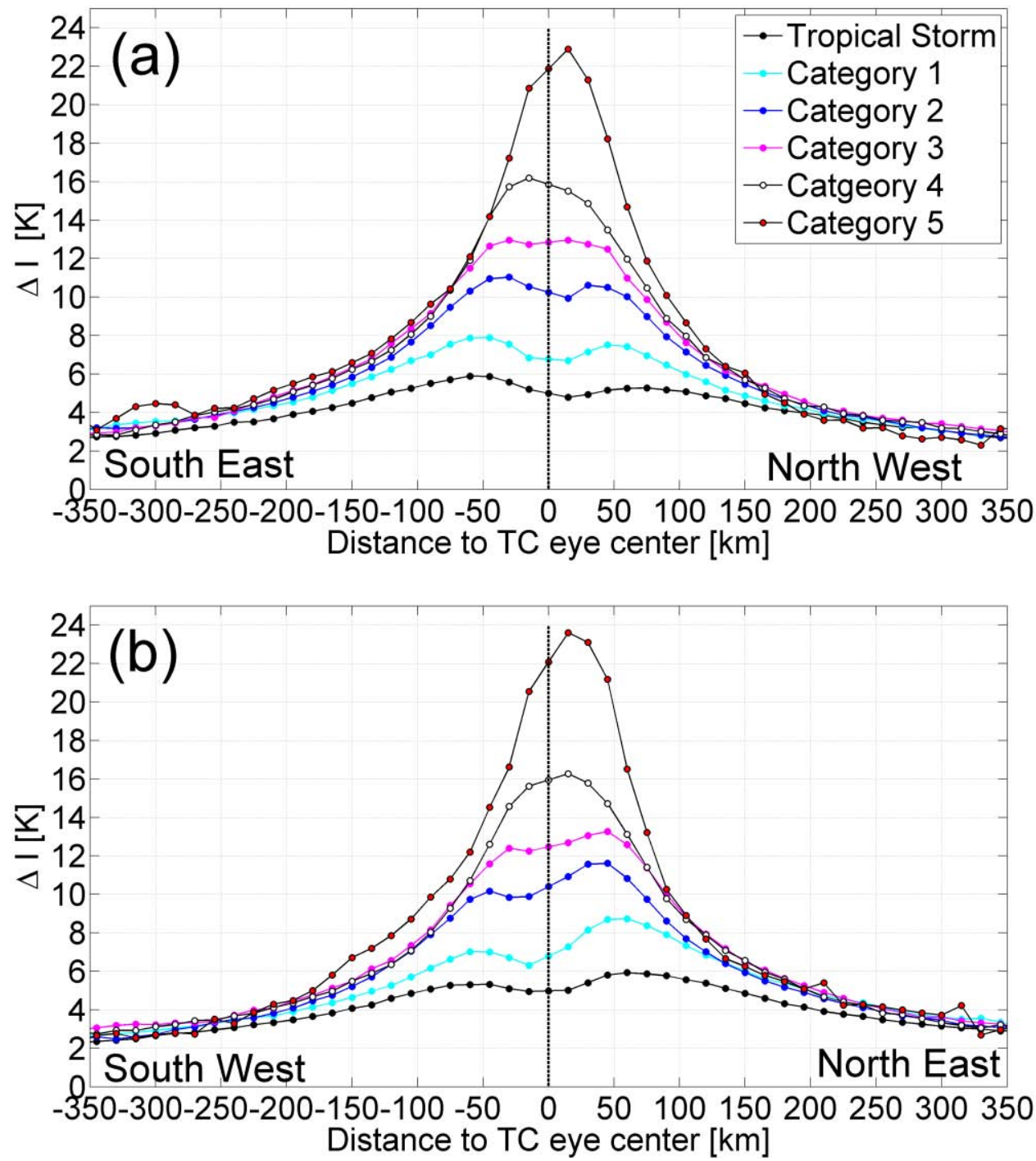

\section{Distance to TC eye center [km]}

Fig. 5. Mean radial distribution of the storm-induced L-band half-power radio-brightness contrasts $(\triangle I[K])$ as function of storm intensities (colors) given by the Saffir Simpson wind Scale (a) from the South East to the North West storm quadrants and (b) from the South West to the North East storm quadrants. 


\section{A revised L-band Geophysical Model Function}

545 The bi-linear GMF relationship 'GMF1' between $\triangle \mathrm{I}$ and the $10 \mathrm{~m}$ height surface wind speed $546 U_{10}$ proposed in Reul et al. (2012) has been inferred solely from observations acquired over a single 547 north-Atlantic hurricane event (Category 4 hurricane Igor in 2010). Using the co-located SMOS, SMFR 548 flight track data and analysed 2D H*Wind fields within our SMOS-STORM database, we have revised 549 the original GMF, hereafter referred to as 'GMF2', as discussed in the following sections.

\section{$550 \quad 4.1 \quad$ Systematic comparisons between SMOS and SFMR}

551 Considering the SMOS-STORM database, we found 64 co-locations between SMOS and SFMR flight 552 tracks in $\sim 30$ TCs over the period 2010-2014. A first SMOS-SFMR paired database was constructed by 553 selecting co-located data with time differences $(\Delta t)$ between both acquisitions of less than \pm 12 hours to 554 provide a large number of pairs. A subset only including pairs with $|\Delta t|<6$ hours was further used to 555 establish statistical relationships between $\operatorname{SMOS} \Delta \mathrm{I}$ and SFMR wind speed. If the central time lag, $\Delta \mathrm{t}$, 556 between SMOS and SFMR data as the aircraft flew over the eye region exceeded $\pm 0.5 \mathrm{~h}$, the storm center 557 displacement between the aircraft and satellite acquisitions could have been significant. To adjust for 558 storm motion when $|\Delta \mathrm{t}|>0.5 \mathrm{~h}$, SFMR tracks were spatially translated (without rotation) from the original 559 storm centre location detected in SFMR data to the storm centre location evaluated at the SMOS time.

560 The SMOS $\triangle \mathrm{I}$ were then further bi-linearly interpolated in space to match the SMFR data at $\sim 3 \mathrm{~km}$ 561 intervals along each SMFR flight track. The geographic distribution of the ensemble of co-located SMOS 562 and SFMR flight tracks is shown in Fig. 6. Only intercepts with storms that developed in the North563 Atlantic and Gulf of Mexico have been processed. 


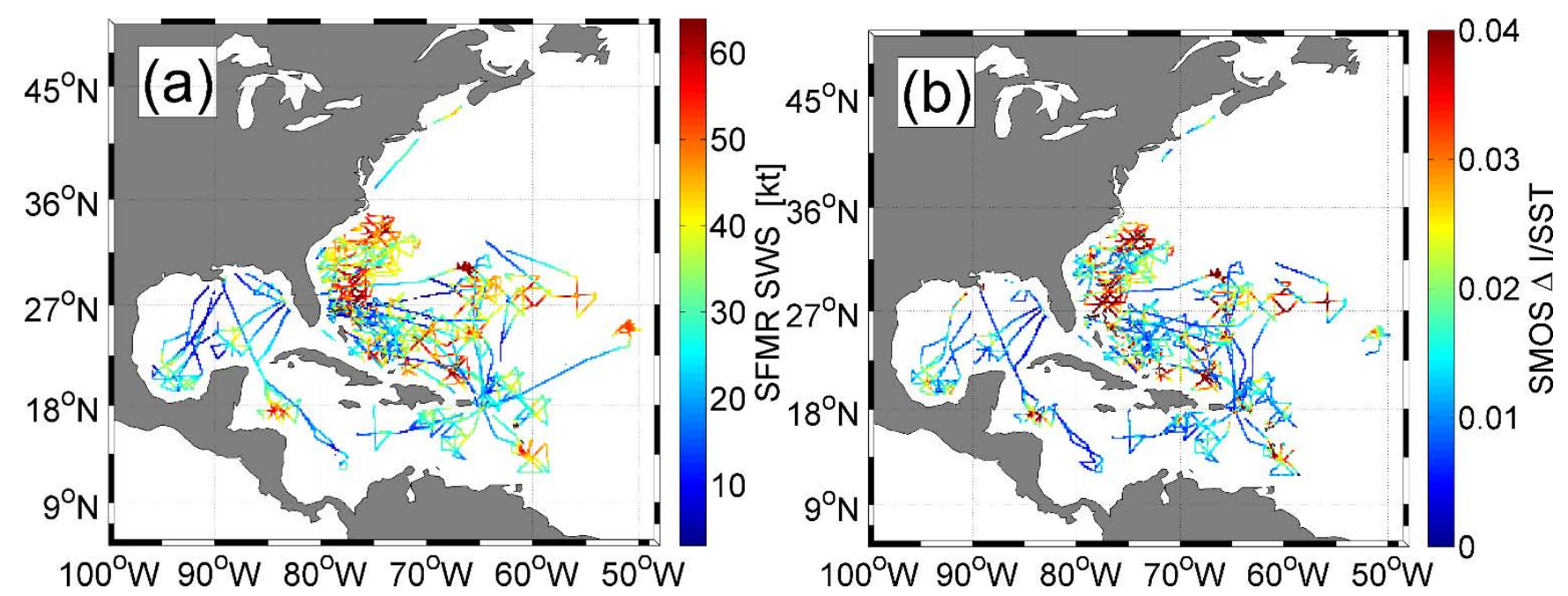

565 Fig. 6. (a) Ensemble of SFMR tracks and associated Wind Speed [knots] used for SMOS-SFMR comparisons, and (b) SMOS L-band excess emissivity $(\triangle \mathrm{e})$ contrasts co-located with SFMR flights.

Given the varying SST conditions encountered for all the storms, in what follows, the SMOS $\triangle \mathrm{I}$ will be now expressed in terms of the storm wind-excess emissivity:

571 Fig. 6 shows that the relative distribution of wind speed measured by SFMR closely match co-located

$572 \operatorname{SMOS} \triangle \mathrm{e}$, with brightest spots in SMOS $\triangle \mathrm{e}$ data almost always spatially coincident with the highest 573 wind regions retrieved along SMFR flights.

574 As a baseline to compare our GMFs, Fig. 7 show representative examples of the co-located surface wind 575 speed retrieved from SMOS using the first GMF (Reul et al., 2012) and second GMF (see below Eq. 7, 576 section 4.2) compared to SFMR estimates. For this comparison SFMR surface wind speed data were 577 spatially averaged along their track using a Gaussian running window of $\sim 43 \mathrm{~km}$ width (blue curves) to 578 better match spatial resolution of SMOS multi-angular data. Both spatially filtered and nominal 579 resolution data are shown for comparisons. The SMOS wind estimates provide a good match to the 580 smoothed SFMR surface wind speed measurements. For the intermediate wind speed range of $\sim 30-60$ 581 kt mismatches and biases are evident that are independent of the time lags between SMOS and SFMR 582 measurements. In high wind gradient regions and zones of high spatial-resolution variability (eg. around 583 the TC eye) detailed structure is not evident in the SMOS data due to the low spatial resolution of the 
584 SMOS instrument. Nevertheless, the match is particularly good in the highest wind speed range in general 585 (e.g., see Fig7.f and h).
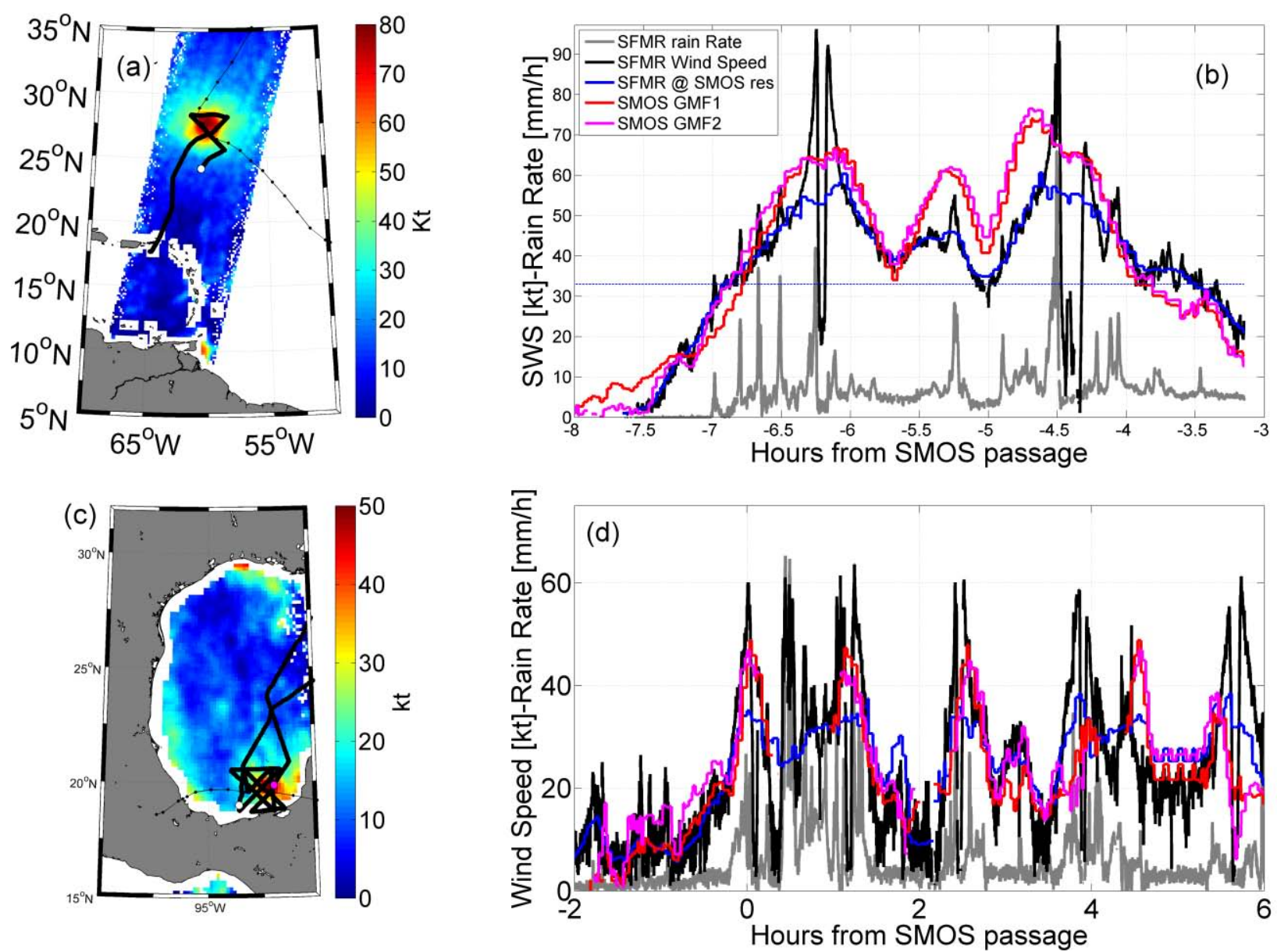

587

588
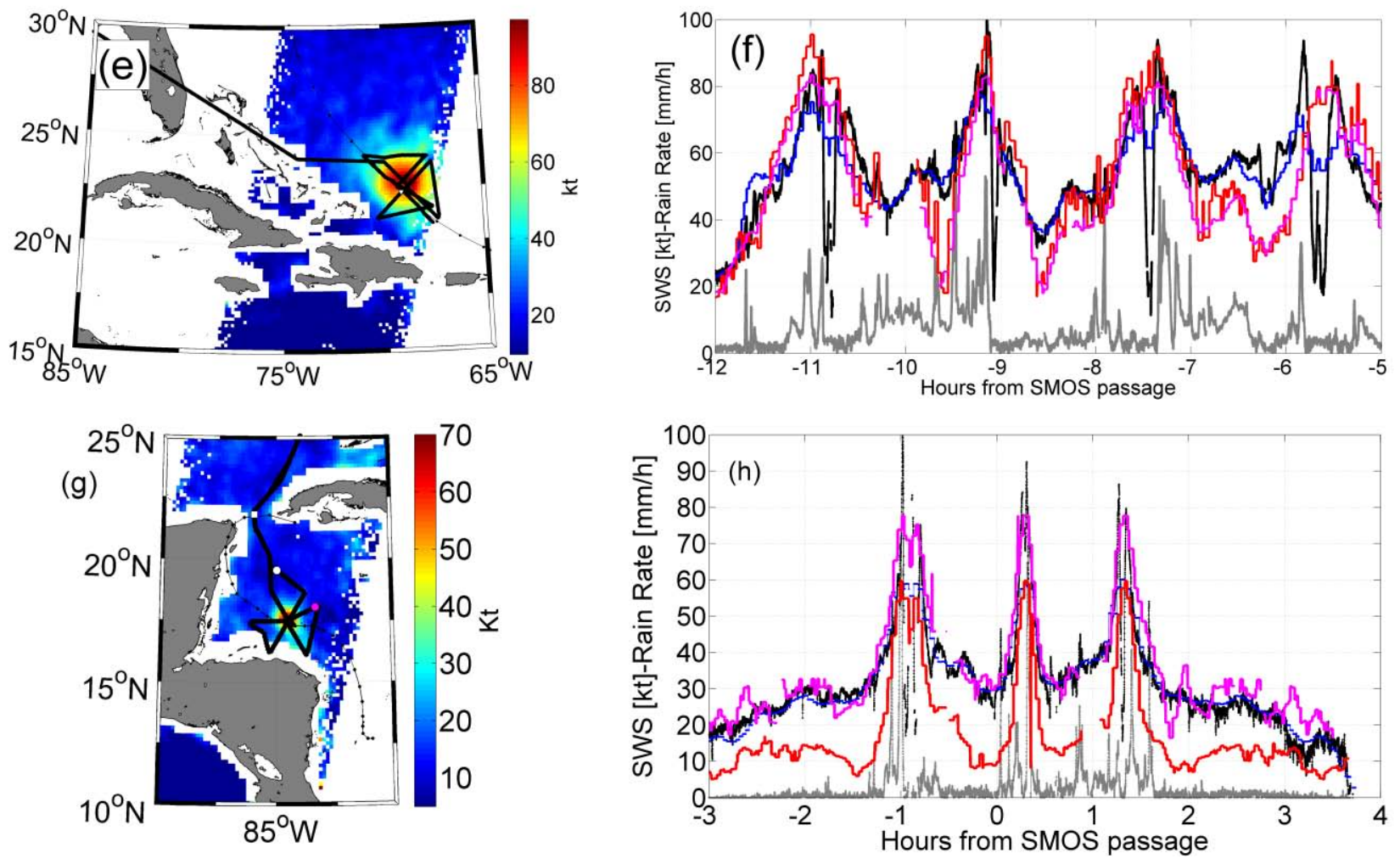


\section{7}

Fig. 7. (a,c,e,g) superimposed SMOS retrieved wind speed using the GMF of Reul et al (2012, color in knots) and SFMR track (black thick curves) for hurricane Daniele the 28 August 2010 (a), hurricane Karl on 16 September 2010 (c); hurricane Earl on 31 August 2010 (e) and hurricane Rina on 25 Oct 2011. The thin dotted curves indicate the storm tracks. b,d,f,h: corresponding time series of the SFMR retrieved wind speed in $\mathrm{m} / \mathrm{s}$ (black curve) and rain rate in $\mathrm{mm} / \mathrm{h}$ (grey curve) at nominal resolution along aircraft track $(\sim 3 \mathrm{~km})$. The SFMR retrieved wind speed has been spatially averaged with a running window of $43 \mathrm{~km}$ width along track (corresponding to the mean resolution of SMOS interferometer pixels) is shown in blue. The retrieved wind speed from SMOS is shown in red using GMF1 and in magenta using GMF2. The $\mathrm{x}$-axis shows the time lag between SFMR acquisitions and SMOS ones.

To minimize the potential impact of structural evolution of the storm between SMOS and SFMR acquisition times, we further selected only those data pairs with $|\Delta t|<6 \mathrm{~h}$ to derive a new GMF. Biases in SFMR wind data induced by high rain-rates were also corrected according to Klotz and Uhlhorn (2014). Fig. 8 shows the storm-induced $\triangle \mathrm{e}$ as function of the co-located SFMR wind speed (spatially smoothed at SMOS resolution and obeying the previous time lag constraint). The median and standard deviation of the $\triangle \mathrm{I}$ values per $10 \mathrm{kt}$-width bins of SFMR wind speed are also provided. For comparison, we show the bi-linear GMF1 from Reul et al., 2012.

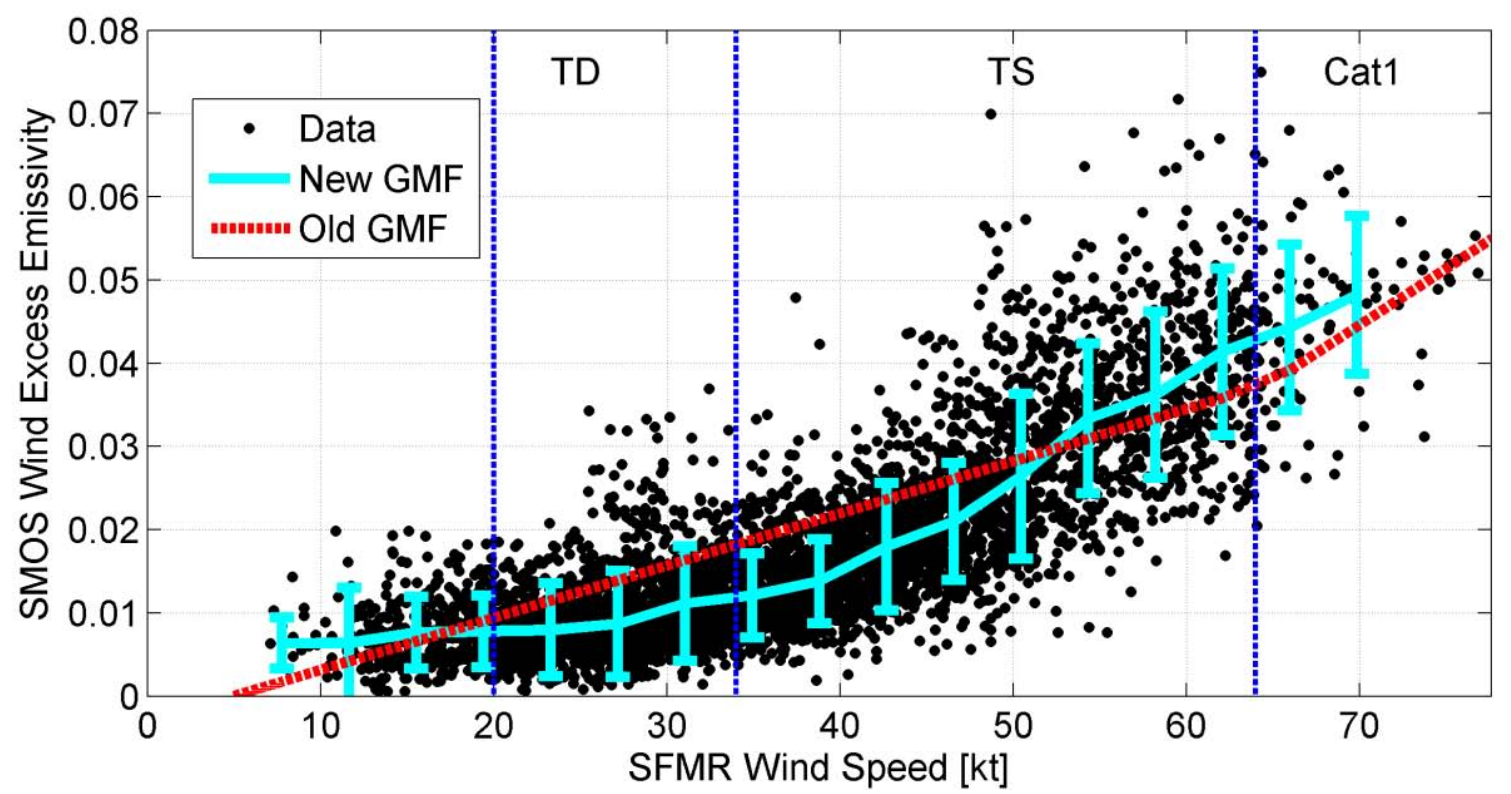

Figure 8: SMOS storm-induced excess L-band emissivity, $\triangle \mathrm{e}$, as function of co-located SFMR wind speed for an ensemble of 64 SMFR flights in the Gulf of Mexico and western Atlantic ocean. The time lags between both observations never exceed $6 \mathrm{~h}$. The red line indicate the first bi-linear GMF proposed in Reul et al. (2012). The cyan curve indicates the mean wind-excess emissivity per $10 \mathrm{kt}$-width bins and the vertical bars indicate \pm 1 standard deviation of the emissivity within each bin.

As can be seen, while rather close to the first bi-linear GMF estimate, the new fit based on SMOS and SFMR wind speed co-located pairs is a nonlinear function of the wind speed. In particular, the new GMF 
617 shows that the storm-induced excess emissivity is almost wind-speed independent for winds below $\sim 20$

618 kt. In the intermediate wind speeds ranging from 20 to $50 \mathrm{kt}$, the new GMF lies below the old linear

619 relationship indicating an underestimation of the retrieved wind speed from SMOS data using the linear 620 empirical law or Reul et al (2012). This is particularly evidenced in Fig 7h, which shows an 621 underestimated SMOS retrieved wind in that range using GMF1, further corrected using GMF2. Note 622 for this particular case that most of the differences between GMF1 and GMF2 is related to the use of 623 climatological SSS for GMF1 and SMOS SSS for GMF2. In the highest wind speed regime ( $>50 \mathrm{kt})$, the 624 new GMF function shows a systematically higher value than the linear approach. It is interesting to note 625 that the new GMF exhibits similar dependencies with wind speed when compared to the excess 626 emissivity vs. wind speed law deduced for the C-band SFMR data (Uhlhorn et al. 2007; Klotz and 627 Uhlhorn, 2014).

\subsection{Systematic comparisons between SMOS and H*WIND}

The SMOS-SFMR co-located dataset (Fig. 7) shows that the Reul et al (2012) linear GMF1 retrieves 630 relatively accurate surface wind speed values from SMOS observations in TCs. However, Fig. 8 also 631 highlights a slightly more non-linear behaviour of the $\Delta \mathrm{e}$ as function of surface wind speed than Reul et 632 al. (2012) which was based on a single TC, particularly in the intermediate (20 to $40 \mathrm{kt})$ and high (>50 $633 \mathrm{kt}$ ) wind speed ranges that would result in under and over estimation of the surface wind speed, 634 respectively.

635 Given the time-lag constraints in the SMOS-SFMR data co-location and data selection used when 636 building the GMF, inevitably only a small number of match-ups were available in the highest wind speed 637 regime with very little data above hurricane force $(>64 \mathrm{kt})$. To increase our confidence in the statistical 638 reliability of the GMF and to increase the quantity of co-located pairs at the highest winds, we constructed 639 an extended database of SMOS $\triangle \mathrm{e}$, retrieved SMOS surface wind speed (using Reul et al (2012) GMF 640 as a first guess) and $\mathrm{H}^{*}$ WIND 2D surface wind speed fields. 30 cases were found for which either SMOS 641 data were available within $< \pm 0.5 \mathrm{~h}$ from an $\mathrm{H}^{*}$ WIND or when the two closest $\mathrm{H}^{*}$ WIND wind fields in 
642 time (before and after a SMOS overpass of a storm) was available within $6 \mathrm{~h}$. In the latter case, an 643 interpolation in time of the two closest storm-centric $\mathrm{H}^{*}$ WIND SWS fields was performed at the SMOS 644 time.

645 For illustration, Fig. 9 and 10 show two examples of SMOS/H*WIND comparisons. Fig. 9 shows the 646 results for Hurricane Leslie as it developed to a TC on 7 September 2012 at 22:19 Z. The RMS difference 647 between SMOS and H*WIND SWS fields is $\sim 7 \mathrm{kt}$. As shown, the structure of both wind fields are very 648 consistent, with maximum winds found in the north-west quadrant at a radial distance of about $150 \mathrm{~km}$ 649 with the maximum wind radii at 34 and $50 \mathrm{kt}$ matching closely between both products in the NW and SE 650 quadrants. Nevertheless, small residual biases are seen in the two other quadrants, with SMOS winds 651 lower than $\mathrm{H}^{*} \mathrm{WIND}$ and a smaller $34 \mathrm{kt}$ radius in the SW quadrant 

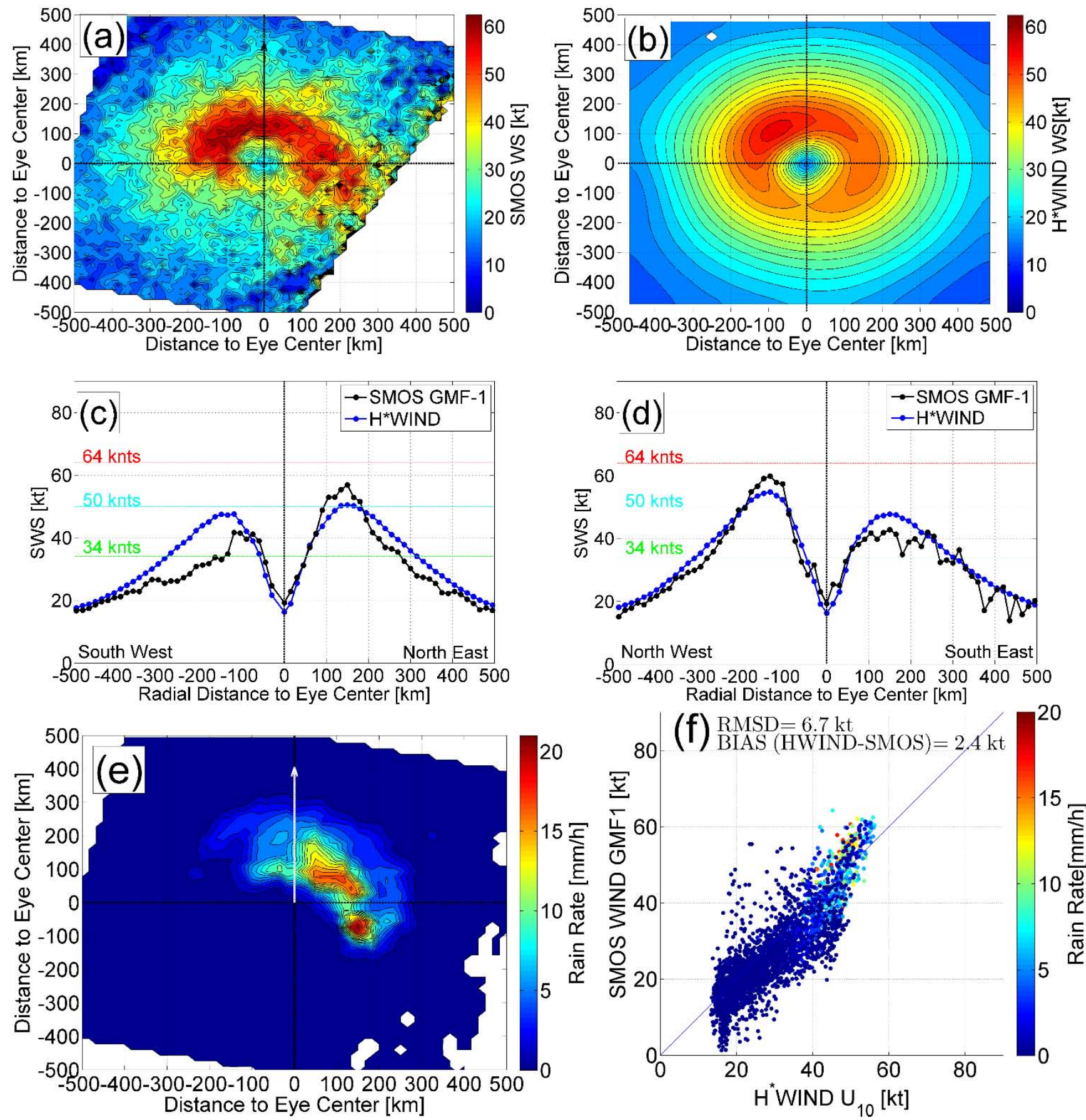

Fig. 9. (a) Surface wind speed retrieved from SMOS (GMF of Reul et al (2012)) in a storm centric coordinate system for hurricane Leslie on 7th September 2012 at 22:19. (b) H*WIND fields interpolated at SMOS acquistion time and spatially averaged at $43 \mathrm{~km}$ resolution. (c) Mean radial distribution of the SMOS (black) and H*WIND (blue) surface wind speed from the SW to the NE storm quadrants, and (d) from the NW to the SE storm quadrants. (e) CMORPH rain rate at SMOS acquisition time. (f) SMOS retrieved wind speed as function of $\mathrm{H}^{*}$ WIND with 660 color indicating the rain rate from $\mathrm{CMORPH}$. 

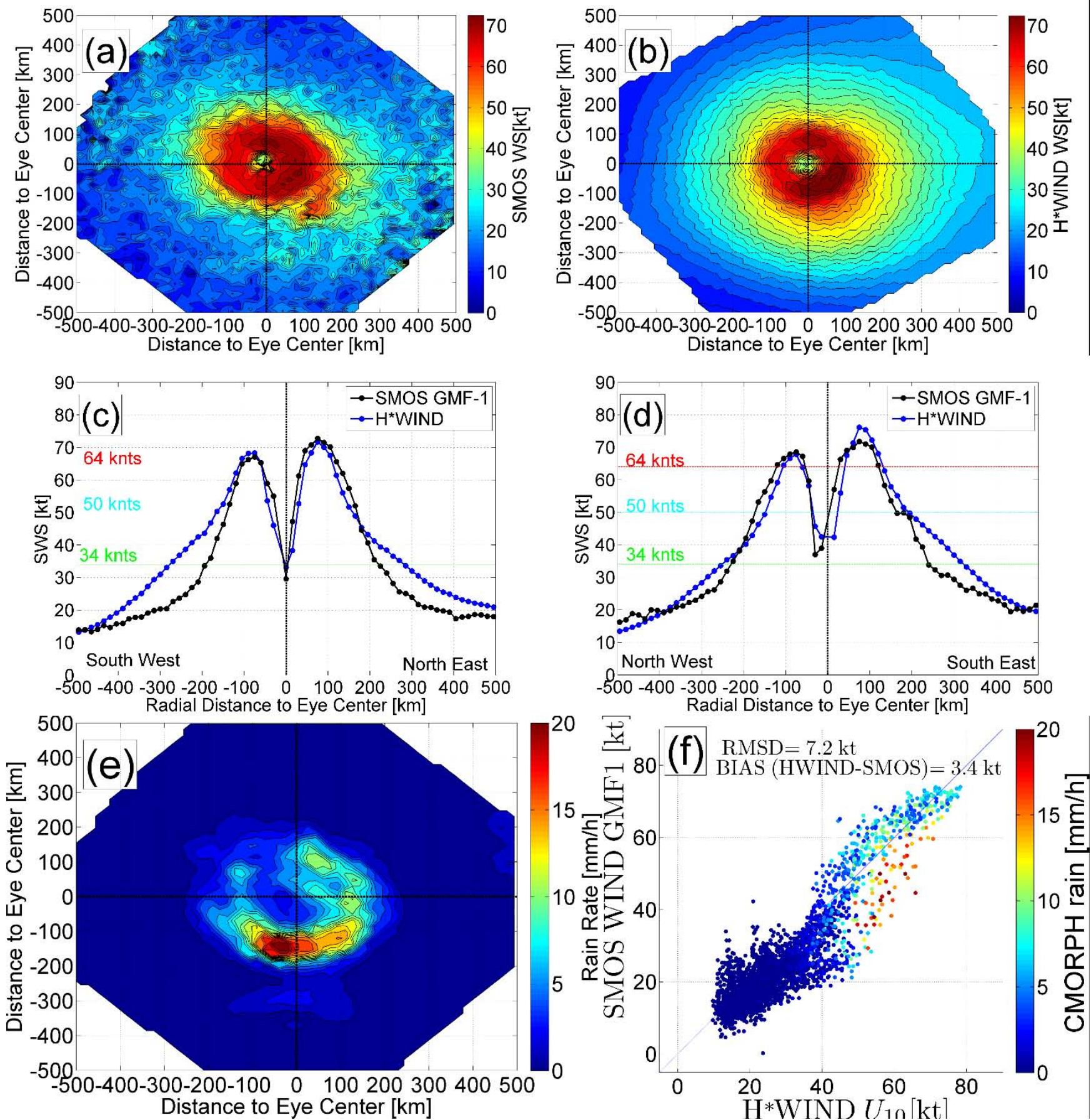

Fig. 10. Same caption as Fig.9 except for the case of hurricane Katia on the $6^{\text {th }}$ September 2011 at 09:35 Z.

671

672 SMOS winds are slightly higher than $\mathrm{H}^{*}$ WIND in the NE quadrant at radial distances between 100 and

$673200 \mathrm{kms}$ (Fig. 9 c,d). Considering the co-located CMORPH data, the rain rate reached more than 20

$674 \mathrm{~mm} / \mathrm{h}$ at some locations in the highest wind speed band found in this quadrant corresponding to retrieved

675 SMOS winds slightly higher than H*WIND (Fig. 9 e, f). 
676 The second example (Fig 10) shows the case of Hurricane Katia as it reached a Category 2 intensity. 677 Here again, the match between both SMOS and H*WIND wind speed fields is rather good in general 678 (RMS $\sim 7.2 \mathrm{kt}$ ), with consistent estimates of the maximum wind radius and value (around $80 \mathrm{kt}$ ), and of 679 the 50 and $64 \mathrm{kt}$ wind radii. However, SMOS retrieved winds at 34 kt exhibit a slightly smaller wind 680 radii than the $H^{*}$ WIND product. This is consistent with the behaviour expected from the bilinear GMF 681 according to SMOS/SFMR matchups. Contrary to the case of hurricane Leslie (Fig.9), the intense rain 682 region (with rain rates $>20 \mathrm{~mm} / \mathrm{h}$ ) is now associated with underestimated SMOS winds with respect $683 \mathrm{H}^{*}$ WIND. As the impact of precipitation is inconsistent it appears that this is not the principal process 684 responsible for the observed biases in SMOS winds versus H*WIND (see Fig. 9 and Fig. 10 e, f).

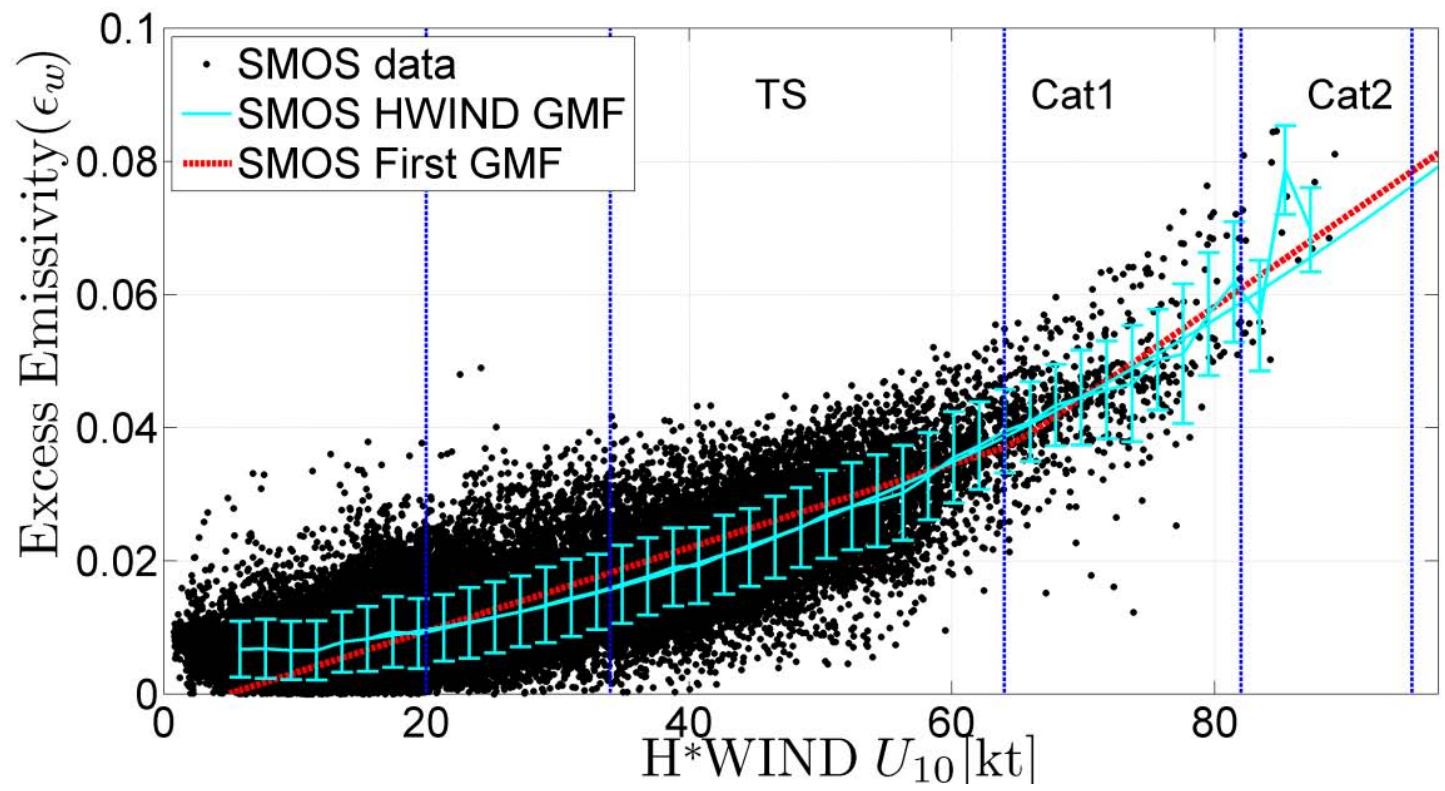

686

687

688

689

690

691

692

693

694

695

696

697

mean SMOS spatial resolution. In between $20 \mathrm{kt}$ and $\sim 50 \mathrm{kt}$, the GMF derived based on $\mathrm{H}^{*}$ WIND fields 
698 shows a very similar structural form to the GMF derived using only SFMR data: it is systematically found 699 lower at a given wind speed than the bi-linear GMF1 of Reul et al (2012). This might be expected as 700 SFMR data are used as key input data to derive the H*WIND analyses. In the wind speed regime over $70150 \mathrm{kt}$, the H*WIND derived GMF is very similar to the GMF of Reul et al (2012), which was not the 702 case for the SFMR matchups. At wind speeds $<\sim 10-15 \mathrm{kt}$ the new GMF shows little sensitivity. A 703 quadratic fit through the data give the following GMF function for the half-power L-band storm-induced 704 brightness temperature contrast as function of the $\mathrm{H}^{*}$ WIND 1-minute sustained surface wind speed 705 averaged at SMOS spatial resolution:

706

$\Delta I\left(U_{10}\right)=S S T \cdot\left(2.7935 \times 10^{-5} U_{10}^{2}+6.8599 \times 10^{-5} U_{10}+0.0059\right)$

707 As H*WIND and SFMR-based fits are very similar in the low to moderate wind speed range and, given

708 the fact that the $\mathrm{H}^{*}$ WIND GMF includes the SFMR data and provides a much larger number of paired 709 data for the high wind regime, we use (Eq. 7) as the new reference GMF for retrieving surface winds 710 from SMOS L-band radio-brightness contrasts data. Hereafter, we referred to this new GMF as GMF2.

\section{$711 \quad 4.3 \quad$ Potential Impact of Rain}

712 The previous GMFs were built assuming that there is no impact of rain and sea state on the L-band 713 contrasts. Using CMORPH co-located 2D observations, all data used to build up the H*WIND derived 714 GMF have been characterized in terms of rain rate. Fig. 12 (top) shows the bin-averaged $\Delta$ e as function 715 of wind speed for rain free and rainy conditions. Unfortunately, data showing rain-free conditions are 716 only available up to a wind speed of $50 \mathrm{kt}$. For surface winds of $>20 \mathrm{kt}$, the rain free $\Delta \mathrm{e}$ at a given wind 717 speed is systematically lower than the equivalent $\Delta \mathrm{e}$ measured in rainy-conditions. The differences in $\Delta$ 718 e between rainy and non-rainy conditions reach a maximum of $\sim 0.01$ at $50 \mathrm{kt}$, which for a typical SST of $71928^{\circ} \mathrm{C}$ would translate into a $3 \mathrm{~K}$ bias in $\Delta \mathrm{I}$ due to rain. 


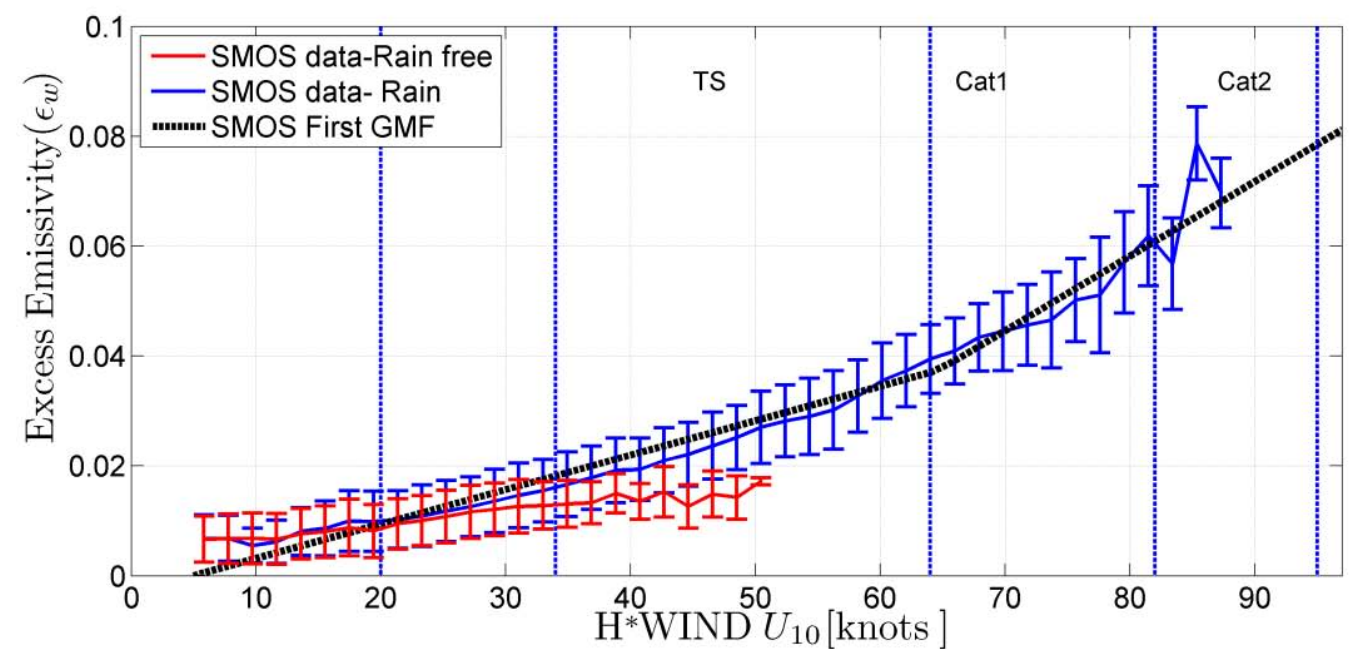

721

722

723

724

725

726

727

728

729

730

731

732

733

734

735

736

737

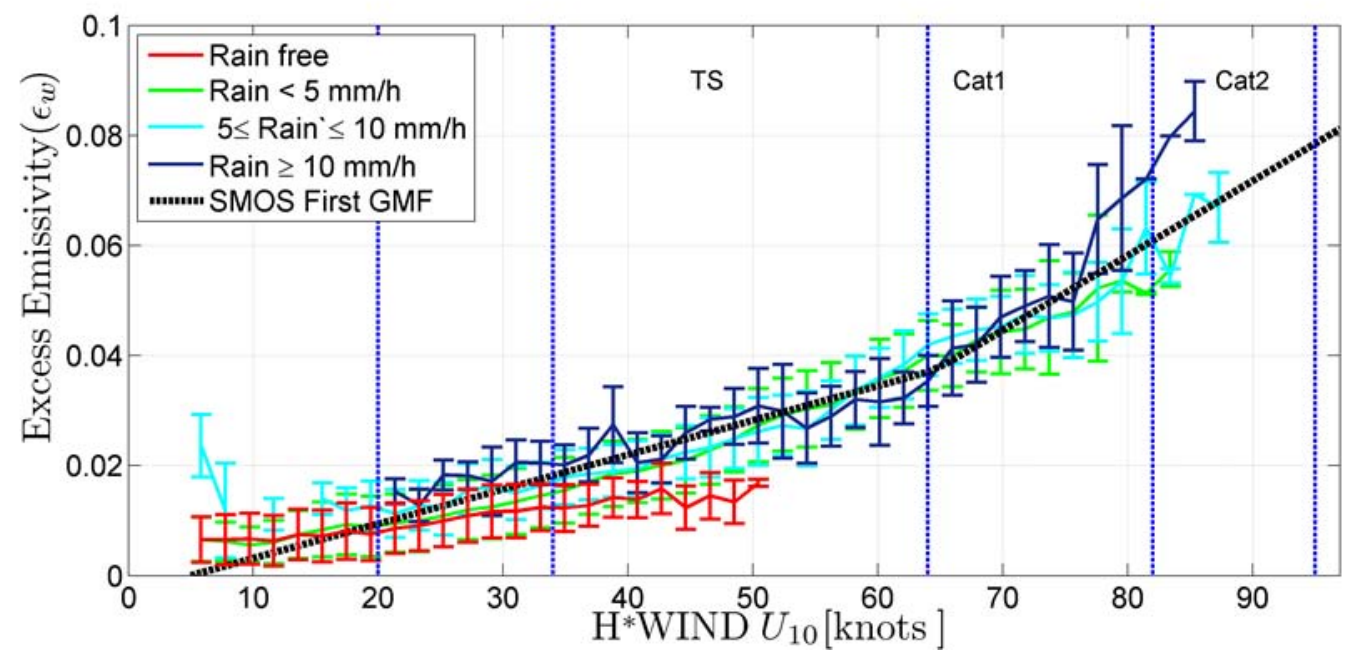

Fig. 12: Potential effects of rain on the excess L-band emissivity $\triangle \mathrm{e}$ in storm conditions. Top: GMF deduced from the SMOS and $\mathrm{H}^{*}$ WIND matchups with rain rate provided from $\mathrm{CMORPH}=0$ (red) and rain rate $>0$ (blue). Bottom: similar caption than for the top plot except that the data are now classified by ranges of rain rate (RR): $R R=0$ (red), $0<R R \leq 5 \mathrm{~mm} / \mathrm{h}$ (green), $5 \mathrm{~mm} / \mathrm{h}<\mathrm{RR}<\leq 10 \mathrm{~mm} / \mathrm{h}$ (cyan) and $\mathrm{RR}>10 \mathrm{~mm} / \mathrm{h}$. (blue).

According to the sensitivity of the GMF $(\sim 0.15 \mathrm{~K} / \mathrm{kt}$ below hurricane force and $\sim 0.3 \mathrm{~K} / \mathrm{kt}$ above $64 \mathrm{kt})$, the rain effect would translate into maximum wind speed retrieval error of $\sim 20 \mathrm{kt}(\sim 10 \mathrm{~m} / \mathrm{s})$ for storms below Category 1 and $10 \mathrm{kt}(\sim 5 \mathrm{~m} / \mathrm{s})$ for storms above. In Fig. 12 bottom panel, we show SMOS excess emissivity $\Delta \mathrm{e}$ further classified as function of rain rate intensity in four classes: no rain, light rain (rain rate $\mathrm{RR}<5 \mathrm{~mm} / \mathrm{h})$, moderate rain $(5 \mathrm{~mm} / \mathrm{h}<\mathrm{RR}<10 \mathrm{~mm} / \mathrm{h})$ and heavy rain (RR $>10 \mathrm{~mm} / \mathrm{h})$. No clear stratification of the $\Delta \mathrm{e}$ as function of increasing rain rate is observed in the data up to $\mathrm{H}^{*}$ WIND value of $\sim 75 \mathrm{kt}$, with all observations in rainy conditions lying close around the bi-linear GMF. This suggests that precipitation is not directly responsible for the difference of emissivity between the rain-free and rainy conditions but perhaps a problem with the classification of rain-free data. The departure observed in Fig. 
73812 at high winds ( $>75 \mathrm{kt})$ and heavy rain conditions $(>10 \mathrm{~mm} / \mathrm{h})$ is likely to be an artefact due to the low 739 number of observations in these conditions although more data are required to draw a firm conclusion.

740 Small ice particles are known to exist between the eye wall and outer rain bands of TC. In addition,

741 graupel ice pellets are often collocated with the radius of maximum tangential wind (Houze et al., 1992).

742 Hurricanes are usually glaciated everywhere above the $-5^{\circ} \mathrm{C}$ vertical level and stratiform cloud areas are

743 dominated by snowflakes at these levels (Black and Hallett., 1986). The variation of ice phase cloud 744 characteristics at the top of TC and the contribution of these clouds and ice hydrometeors to the L-band 745 emission might be a plausible source for the observed rain/rain-free differences in $\Delta \mathrm{e}$. Nevertheless, to 746 the authors knowledge no suitable data characterizing the upper atmosphere in terms of ice-phase content 747 is available to estimate that effect.

\section{$748 \quad 4.4 \quad$ Validation of SMOS winds and relative accuracy with ECMWF and NCEP}

749 The SMOS GMF given in Eq. 7 was derived based on an ensemble of $30 \mathrm{H}^{*}$ WIND products, covering 750 about 20 storms in the Atlantic and Gulf of Mexico over several years. Validating the new GMF with the $751 \mathrm{H}^{*}$ WIND data is of little practical value as the $\mathrm{H}^{*}$ WIND data are used to derive the GMF. Instead, we 752 assess the performance of SMOS-derived winds using Numerical Weather Prediction (NWP) products 753 and the 30 collected $H^{*}$ WIND fields as the validation dataset. ECMWF and NCEP surface winds have 754 been co-located with the 30 pairs of SMOS-H*WIND data fields. Residual rain or ice effects degrading 755 the quality of the retrievals as discussed in the previous section are ignored, as there is no methodology 756 to correct for these effects. The difference between $H^{*}$ WIND and the SMOS surface wind speed were 757 evaluated using the bilinear GMF function (GMF1) that was quasi-independently derived from the $758 \mathrm{H}^{*}$ WIND dataset used for here validation. SMOS, ECMWF and NCEP surface winds are compared to 759 the reference H*WIND field in Fig. 13. Compared to Reul et al. (2012) this validation approach will 760 provide a more reliable assessment of the relative quality of SMOS wind speed products because it is 761 based on a significantly larger ensemble of data. 


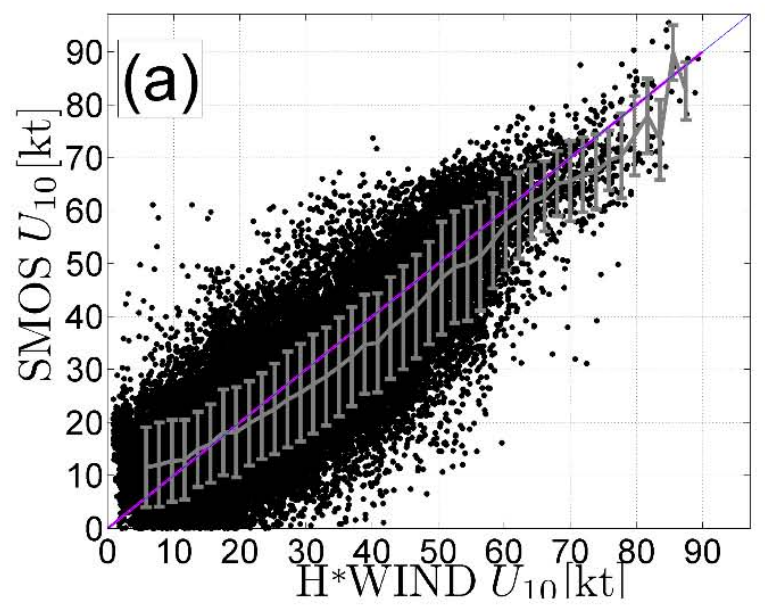

762

763

764

765

766

767

768

769

770

771

772

773

774

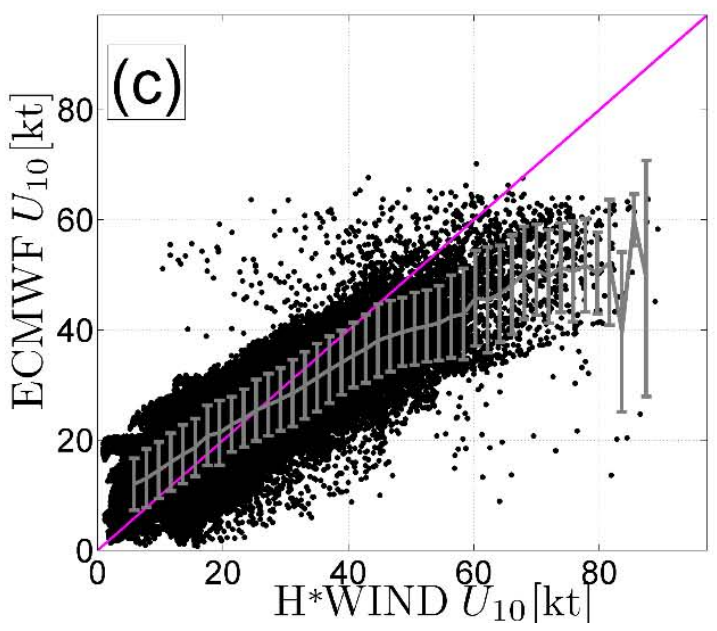
data are provided in Table 1.
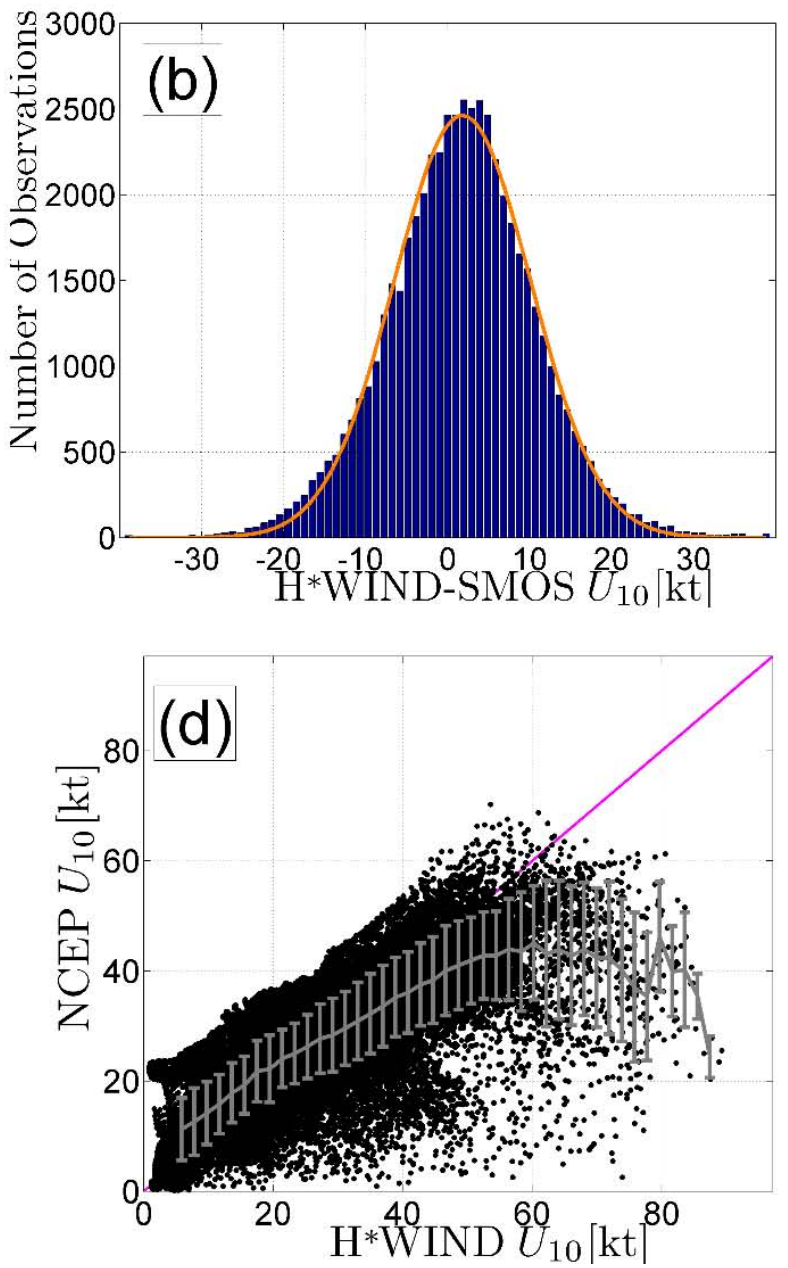

Fig. 13: (a) Comparisons between co-located SMOS retrievals (GMF1) and $H^{*}$ WIND surface winds for an ensemble of $\sim 30$ tropical storms and hurricanes over the period 2010-2013 (b) Histogram of the differences between co-located SMOS and H*WIND surface winds. The orange curve is a Gaussian fit with standard deviation of $8.3 \mathrm{kt}$. (c) $\mathrm{H}^{*}$ WIND versus ECMWF winds and (d) NCEP winds versus $\mathrm{H}^{*}$ WIND. The gray curves are showing the mean $\mathrm{y}$-axis wind speed in bins of $2 \mathrm{kt}$ width of $\mathrm{H}^{*} \mathrm{WIND}$ surface wind speed data \pm 1 standard deviation. Root mean square differences (RMSD) and biases between each products and $\mathrm{H}^{*}$ WIND ones are provided in table 1.

Statistics of the differences between these three estimates of the surface wind speed in TCs and $\mathrm{H}^{*}$ WIND 
Table-1. Statistics of the differences between co-located H*WIND and SMOS, ECMWF and NCEP surface wind fields (positive mean difference means that $\mathrm{H}^{*} \mathrm{WIND}$ is greater than the considered product).

\begin{tabular}{|c|c|c|c|c|}
\hline & Wind Speed Range (kt) & SMOS & ECMWF & NCEP \\
\hline RMSD (kt) & $0-100$ & 9.3 & 7.9 & 8.9 \\
\hline Mean difference (kt) & $0-100$ & 1.5 & 0.9 & 0.4 \\
\hline RMSD (kt) & $64-100$ & 8.1 & 23.5 & 32.4 \\
\hline Mean difference (kt) & $64-100$ & 4.3 & 21.6 & 29.2 \\
\hline
\end{tabular}

784

As shown in Table-1, the RMS and mean differences between $\mathrm{H}^{*}$ WIND products and the three surface wind speed products are very similar considering the full wind speed range between 0 and $100 \mathrm{kt}$. However, above $\sim 64 \mathrm{kt}$, the SMOS wind speed accuracy outperforms NWP winds with rms and mean differences between SMOS and $\mathrm{H}^{*}$ WIND data of about $8.1 \mathrm{kt}$ and $4.3 \mathrm{kt}$, respectively whereas both NCEP and ECMWF products both saturate with increasing wind speed leading to significant biases and root mean square differences greater than $20 \mathrm{kt}$ in the high wind speed range when compared to H*WIND.

We have shown that the 'average' L-band brightness temperature excess is a monotonically increasing parameter with increasing storm intensity. The highest wind regions often extending over domains of, or smaller than, $100 \mathrm{~km}$, with very significant wind speed gradients found over small distances relative to the SMOS spatial resolution, particularly in the eyewall region. Given the relatively low spatial resolution of the SMOS instrument $(\sim 43 \mathrm{~km})$ maximum sustained wind speeds, a key parameter in all parameterization of hurricane wind field dynamics, are retrieved from SMOS but lacking small-scale features (this was clearly seen when comparing SMOS wind retrievals with SFMR aircraft measurments). 


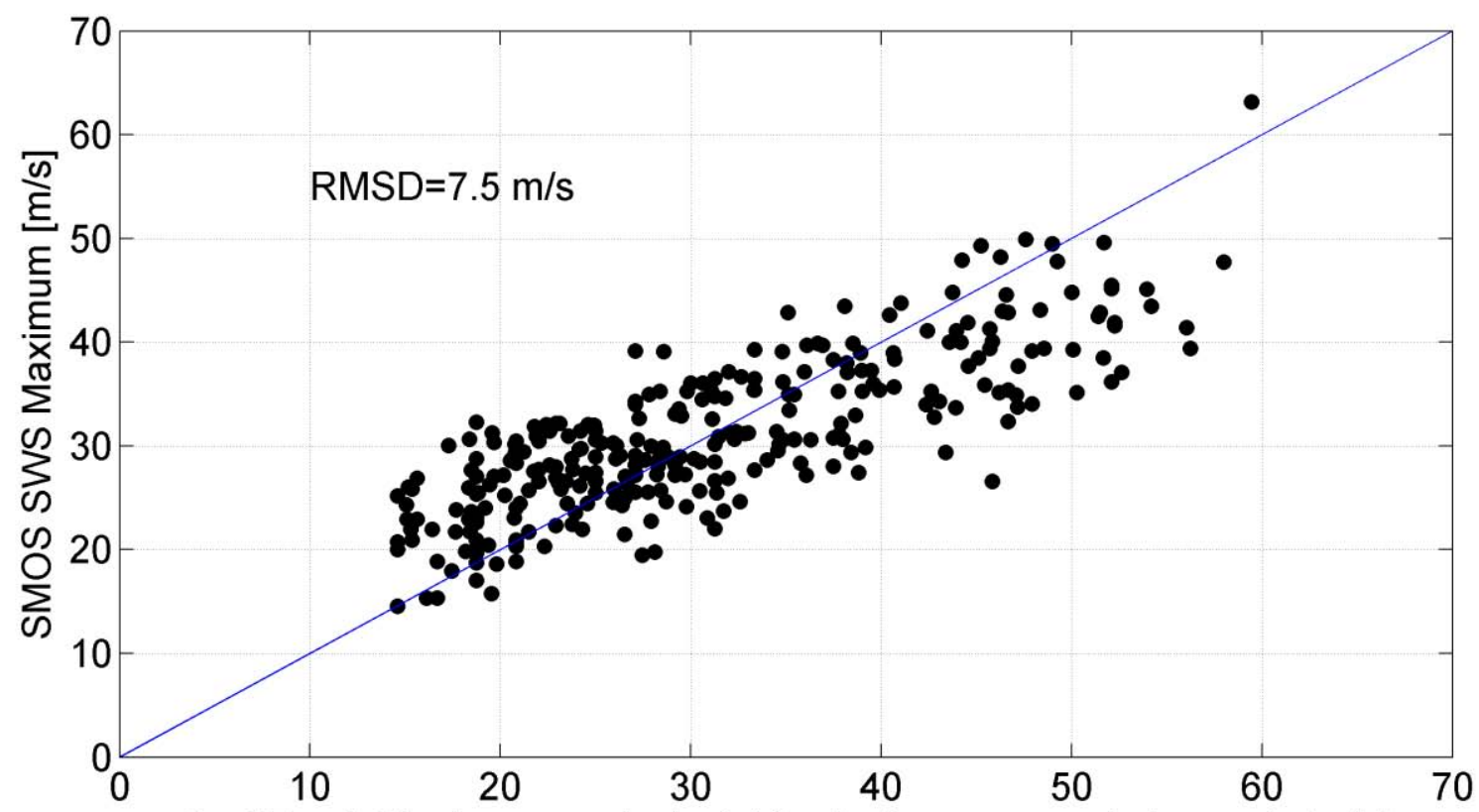

Best Track Maximum equivalent 10-minute average wind speeds [m/s]

Figure 14: Relationships between the maximum of SMOS winds as function of the Best track Maximum Sustained Wind speed.

To assess the quality of the maximum wind speed inferred from SMOS products, we compared the maximum wind derived from Eq. 7 computed for each of the 300 storms in the SMOS-STORM database to the 6-hourly Best Track maximum wind interpolated to the SMOS acquisition time. The comparison between both estimates is shown in Fig. 14 which shows that the maximum wind derived from SMOS correlates well with the Best-track maximum sustained wind. The RMS difference is nevertheless higher than it was found for all-wind speed comparisons, reaching $14.5 \mathrm{kt}$. An underestimation of the maximum wind is also systematically visible in the SMOS products above $\sim 75 \mathrm{kt}$. The spatial-smoothing effect of the satellite sampling, with a predominant impact in the very high wind and high gradient regions is thought to be the cause of this underestimation.

\section{Conclusions and perspectives}

Five years (May 2010- April 2015) of SMOS L-band brightness temperature data intercepting a large

15 number of Tropical Cyclones at global scale have been analysed in this paper. A subset of about 300 intercepts have been carefully selected to provide the highest quality measurements available covering the full range of storm intensities on the Saffir-Simpson Wind Scale. The storm-induced half-power 
818 radio-brightness contrast, $\triangle \mathrm{I}$, was estimated for each SMOS intercept with storms and expressed in a

819 common storm-centric coordinate system. The 2D mean and standard deviation of the $\Delta \mathrm{I}$ were further

820 evaluated for each storm intensity class of the Saffir-Simpson Wind Scale. The average distribution of $\Delta$

821 I show that the mean brightness contrast amplitude coherently increases with increasing TC intensity.

822 The radii within which the brightest $\triangle \mathrm{I}$ values are found for each TC category is found to diminish as

823 the storm intensity increases, consistent with the reported evolution of the highest surface wind 824 distribution in TC (Holland, 1980). The mean brightness contrast is monotonically increasing with storm 825 intensities from about $5 \mathrm{~K}$ for tropical storms up to $\sim 24 \mathrm{~K}$ for the most intense category 5 cyclones 826 without showing saturation above hurricane force $(64 \mathrm{kt})$ illustrating the potential of the SMOS data for 827 better monitoring TC intensification. A remarkable feature of the mean $\Delta \mathrm{I}$ fields is that the maxima of $828 \Delta \mathrm{I}$ are systematically found on the right-hand side quadrants of the storms. This is consistent with the 829 reported asymmetric structure of the wind and wave fields in TC conditions: the maximum wind speed 830 and sea surface height generally occur in the right-hand quadrants of storms (in the northern-hemisphere) 831 because of the relative wind and extend-fetch effects created by a translating storm. For category $1-5$ 832 TCs, the $\triangle \mathrm{I}$ standard-deviation exhibits a quasi-annular distribution around the storm centre, with local 833 minima at the centre, consistent with the relatively calm eye of a TC. For storm intensities above and 834 including category 4 on the Saffir Simpson Wind Scale, the SMOS instrument is not able to resolve the 835 detailed structure of TC eye winds for those most intense storms that have a maximum wind radii below 836 the SMOS pixel size $(\sim 43 \mathrm{~km})$.

837 A revision of the bi-linear GMF proposed by Reul et al. (2012) has been derived using a much larger 838 ensemble of co-located SMOS, SMFR flight track data and analysed 2D $\mathrm{H}^{*}$ Wind fields. We found that 839 the L-band radio-brightness contrast evolves quadratically with surface wind speed and we propose an 840 empirical parametric law relating $\Delta \mathrm{I}$ and the $10 \mathrm{~m}$ height surface wind speed $U_{10}$. Major differences 841 with the GMF of Reul et al. (2012) are found in the low to moderate wind speed regimes. Use of the new 842 GMF will help reduce observed biases in the SMOS surface wind retrievals below $50 \mathrm{kt}$. 
Using co-located rain rate estimates from CMORPH, we shown that the L-band radio-brightness

844 contrasts measured in TC rain-free conditions do not evolve similarly with wind speed compared to those

845 acquired during precipitation events. Differences as large as $3 \mathrm{~K}$ translate into maximum surface wind

846 speed errors of $\sim 20 \mathrm{kt}$ below hurricane force $(\sim 64 \mathrm{kt})$ and $\sim 10 \mathrm{kt}$ above. Larger errors are found in the

847 lowest wind speed regime because of the smaller sensitivity of the $\Delta \mathrm{I}$ function to wind speed below

848 hurricane force. However, further classification of these data as function of increasing rain rate for fixed

849 wind speed values did not reveal any significant dependencies with increasing rain rate. This seems to

850 indicate that other geophysical contributions are responsible for the observed differences in $\Delta \mathrm{I}$ during

851 rain-free and rainy conditions. The variation of ice phase hydrometeor characteristics at the top of

852 cyclones and the associated varying contributions of clouds to the L-band emission might be a plausible 853 source.

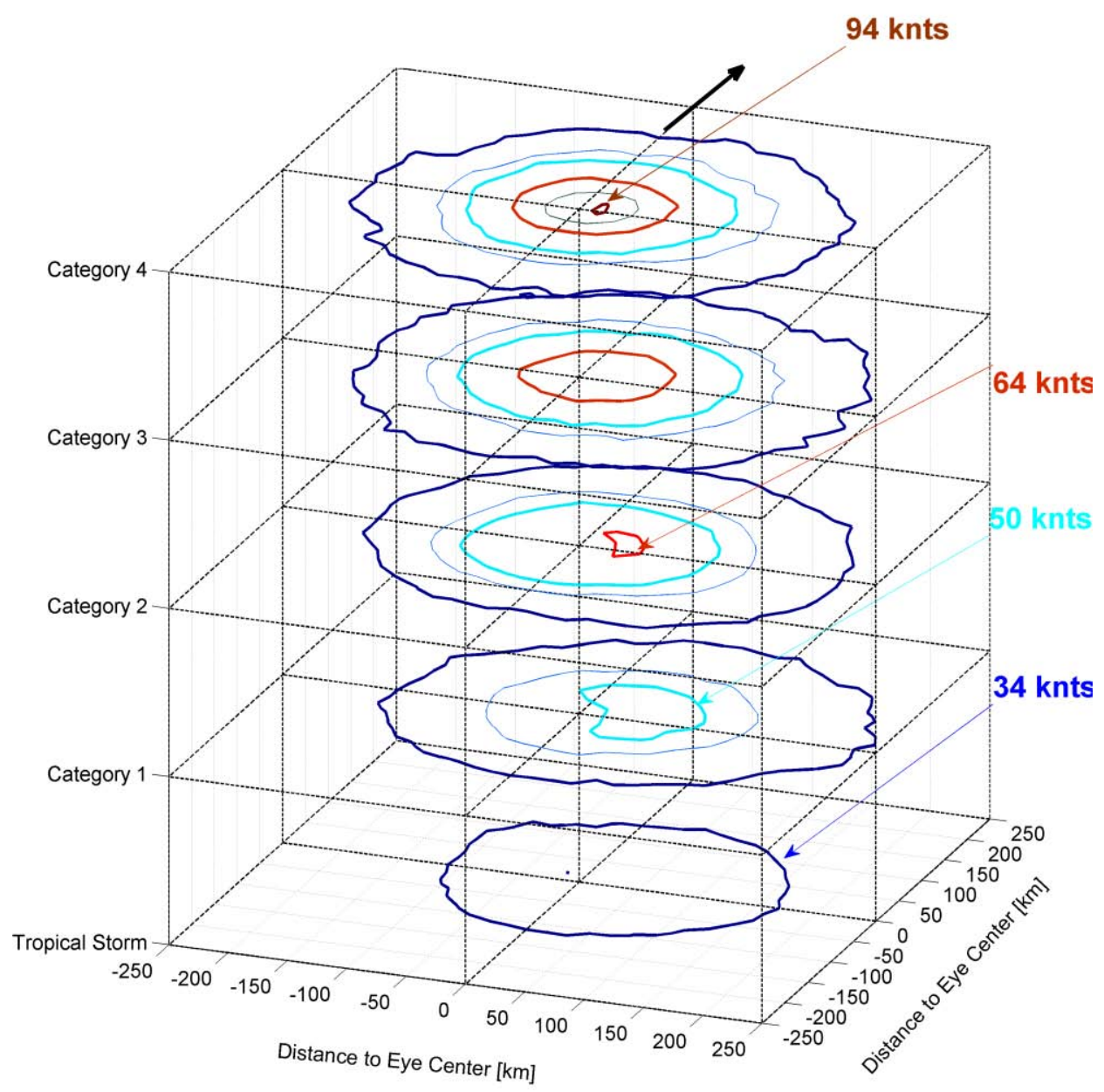

Fig. 15. Synoptic structure of the surface wind field in Tropical Cyclones as retrieved from SMOS data as function of the Saffir-Simpson High Wind intensity scale. Average 2D wind fields from SMOS are 
857 contoured at levels of 34 (thick dark blue), 44 (thin blue), 50 (thick cyan), 64 (thick red), 80 (gray) and 85894 (thick chesnut) kt. The thick black arrow is indicating the averaged storm propagation direction.

Neglecting the potential rain/ice impacts, we compared SMOS, ECMWF and NCEP winds to a large 862 ensemble of $\mathrm{H}^{*}$ WIND 2D fields spatially averaged at the SMOS $\sim 43 \mathrm{~km}$ nominal spatial resolution. 863 Using the GMF of Reul et al. (2012), results showed that the surface wind speed in TCs can be retrieved 864 from SMOS data with an RMS error on the order of 8-9 kt up to $100 \mathrm{kt}$. Better performance is expected 865 with a new quadratic GMF. SMOS wind product performances when compared to H*WIND 'ground866 truth" data in the hurricane wind speed range (above $64 \mathrm{kt}$ ) are found to be a factor 3 to 4 better than the 867 those from the NWP products: NWP fields significantly underestimating the surface wind speed in 868 extreme conditions. The maximum wind speed estimated from SMOS was shown to be consistent with 869 best-track wind analysis estimates with and RMS error of $\sim 14$ kts. This degraded accuracy for the wind 870 maxima is thought to be caused by 1) the spatial-smoothing effect of the SMOS instrument sampling in 871 the high-wind gradient zones of the eyewalls and 2) a potentially higher effect of cloud ice and cloud on 872 the L-band emissivity in these regions.

Applying the new quadratic GMF function to the average radio-brightness contrasts estimated as

874 function of storm intensities, we are now in a position to provide a synoptic view of the surface wind 875 field observed by an L-band passive sensor in tropical cyclones. This allows us to study TC structural 876 evolution as function of increasing TC intensities as shown in Fig 15. As the storm intensity increases, 877 the wind speed above a certain threshold spreads within a quasi-circular domain of almost constant radii: $878 \sim 200 \mathrm{~km}$ for winds above $34 \mathrm{kt}, 120 \mathrm{~km}$ for winds above $50 \mathrm{kt}$ and $\sim 75 \mathrm{~km}$ for winds above $64 \mathrm{kts}$ 879 Following the approach of Chavas et al., (2015) who used historical datasets of QuickSCAT satellite 880 scatterometer observations to analyse the wind structures in the outer region of tropical cyclones at large 881 radii, the SMOS synoptic wind structure could be used to assess the quality of available Hurricane wind 882 models (e.g. Holland, 1980) for almost the complete radial structure of the low-level tropical cyclone 883 wind field. 
Average 2D wind fields from SMOS show that the radii of the most intense winds always start to

885

886

887

888

889

890

891

892

893

894

895

896

897

898

899

900

901

902

903

904

905

906

907

908

909

appear on the right-hand (N. Hemisphere) quadrants of the storms for a given intensity. An important result of this study is that the average L-band brightness temperature systematically indicates maxima in the right-hand (N. Hemisphere) quadrants of the storms above hurricane force. This is consistent with reported structures in TC wind models but waves and associated generation of foam are also known to show large asymmetries in storm quadrants with clearly evidenced maxima in significant wave height found in the right-hand (N. Hemisphere) quadrants because of the 'extended-fetch' effect (Young, 2003). The relative contributions of wind and waves to the increase of L-band radio-brightness contrasts remain uncertain and need further detailed investigation e.g., using systematic co-localizations between SMOS data, ground-truth surface winds, and wind and sea state measurements from altimeters (Quilfen et al., 2011). A very promising perspective is the creation of a passive low-microwave frequency-based surface wind speed storm catalogue to be built by merging data from SMOS, AMSR2 and SMAP sensors to provide an enhanced storm tracking capability. SMOS data provide a global coverage about every 3 days.

However, during fast evolving storm events, SMOS may just capture a portion of the storm or miss it entirely. In addition, SMOS data can be heavily contaminated in some areas by RFI, solar effects or land contamination. RFI are particularly problematic in the North west Pacific and in the Bay of Bengal. Combining SMOS, SMAP and AMSR2 retrievals will definitively help better characterizing high wind speed and storm events over the globe. These are on-going efforts within the European Space Agency (ESA) SMOS-STORM project.

With the recent development of new methodologies to retrieve surface wind speed in all weather conditions from X, C and L-band radiometer measurements from Space (Meissner and Wentz, 2009; ElNimri et al., 2010, Reul et al., 2012, Zabolotskikh, 2015) the synergy of passive microwave observations from space operating in the X to L-bands (AMSR2, WindSat, SMOS and SMAP) can now be envisaged. The complementarity and added-value to scatterometer data (eg. ASCAT and RapidSCAT) and NWP products (ECMWF and NCEP) is obvious and will be studied in more detail in the frame of our on-going study. Ultimately we aim to produce new blended surface wind speed products from all products 
910 including the SMOS high wind speed data building on the new methodology currently developed by

911 Zabolotskikh et al. (2015). For SMAP, a similar algorithm than the one presented in this paper for SMOS 912 can be applied.

913 On-going efforts are also in progress to demonstrate the utility, performance and impact of SMOS914 STORM products on TC and extratropical storm prediction systems in the context of maritime 915 applications. Comparisons of the SMOS wind speed data with short range forecasts of $10 \mathrm{~m}$ winds from 916 the Met Office global model background are now performed to generate observed minus background 917 values (O-B). The impact of assimilating SMOS wind speeds will be demonstrated by diagnosing 918 changes to the mean global atmospheric analyses e.g. low-level wind field, pressure at mean sea level 919 (PMSL), etc. Comparing various forecast variables (e.g. wind, surface pressure, geopotential height) with 920 quality-controlled observations valid at the same time/location and calculating the difference in root 921 mean square (RMS) error between the trial and control values will be conducted to show how changes 922 in the analysis as a result of assimilating SMOS wind speed observations affect global model forecasts 923 (so-called global NWP index).

\section{$924 \quad 6$ ACKNOWLEDGEMENTS}

926 We would like to acknowledge the support of ESA Support to Science Element program under the 927 contract SMOS+STORM evolution, \#4000105171/12/I-BG. 


\section{REFERENCES}

Anguelova, M.D.; Gaiser, P.W. Dielectric and Radiative Properties of Sea Foam at Microwave Frequencies: Conceptual Understanding of Foam Emissivity. Remote Sens. 2012, 4, 1162-1189.

Anterrieu, E., P. Waldteufel, and A. Lannes (2002), Apodization functions for 2-D hexagonally sampled synthetic aperture imaging radiometers, IEEE Trans. Geosci. Remote Sens., 40(12), 2531-2542, doi:10.1109/TGRS.2002.1176146

Black, R.A., and J. Hallett (1986), Observations of the distribution of ice in hurricanes" J. Atmos. Sci, 43, pp. $802-822$

Brinkman, S., and Bodschwinna, H. (2003). Advanced gaussian filters. Advanced techniques for assessment surface topography. Kogan Page, London, 63-91.

Camps, A., et al. (2005), The emissivity of foam-covered water surface at L-band: Theoretical modeling and experimental results from the FROG 2003 field experiment, IEEE Trans. Geosci. Remote Sens., 43, 925-937, doi:10.1109/TGRS.2004.839651

Chavas, D. R, N. Lin, and K. A. Emanuel (2015), A model for the complete radial structure of the tropical cyclone wind field. Part I: Comparison with observed structure, Journal of the Atmospheric Sciences, doi: http://dx.doi.org/10.1175/JAS-D-15-0014.1

Donlon, C. J., M. Martin, J. D. Stark, J. Roberts-Jones, E. Fiedler and W. Wimmer, (2012), The Operational Sea Surface Temperature and Sea Ice analysis (OSTIA), Remote Sensing of the Environment, 116, 140-158, doi: 10.1016/j.rse.2010.10.017 2011.

Donnelly, W. J., J. R. Carswell, R. E. McIntosh, P. S. Chang, J. Wilkerson, F. Marks, and P. G. Black (1999), Revised ocean backscatter models at C and Ku band under high-wind conditions, J. Geophys. Res., 104(C5), 11485-11497, doi:10.1029/1998JC900030.

El-Nimri, S. F., W. Lindwood Jones, E. Uhlhorn, C. Ruf, J. Johnson, and P. Black (2010), An improved C-band ocean surface emissivity model at hurricane-force wind speeds over a wide range of Earth incidence angles, IEEE Geosci. Remote Sens. Lett., 7, 641-645, doi:10.1109/LGRS.2010.2043814.

Entekhabi, D., S. Yueh, P. O'Neill, K. Kellogg et al., SMAP Handbook, JPL Publication JPL 400-1567, Jet Propulsion Laboratory, Pasadena, California, 182 pages, 2014. - See more at: https://www.cuahsi.org/Posts/Entry/11508\#sthash.K9plxnN0.dpuf

Golbraikha E. and Y. M. Shtemler, Foam input into the drag coefficient in hurricane conditions, Dynamics of Atmospheres and Oceans, Vol 73, pp 1-9, 2016, ISSN 0377-0265, http://dx.doi.org/10.1016/j.dynatmoce.2015.10.005..

Holthuijsen, L. H., M. D. Powell, and J. D. Pietrzak (2012), Wind and waves in extreme hurricanes, J. Geophys. Res., 117, C09003, doi:10.1029/2012JC007983.

Holland G. J., 1980: An Analytic Model of the Wind and Pressure Profiles in Hurricanes. Mon. Wea. Rev., 108, 1212-1218. doi: http://dx.doi.org/10.1175/1520-0493(1980)108<1212:AAMOTW>2.0.CO;2 
989 Horstmann, J., C. Wackerman, S. Falchetti, and S. Maresca. 2013. Tropical cyclone winds retrieved from 990 synthetic aperture radar. Oceanography 26(2):46-57, http://dx.doi.org/10.5670/oceanog.2013.30.

991 Houze, R. A., Jr., P. V. Hobbs, K. R. Biswas, and W. M. Davis, 1976: Mesoscale rainbands in 992 extratropical cyclones. Mon. Wea. Rev., 104, 868-878.

993 Houze, R. A., Jr., F. D. Marks, Jr., and R. A. Black, 1992: Dual-aircraft investigation of the inner core 994 of Hurricane Norbert. Part II: Mesoscale distribution of ice particles. J. Atmos. Sci., 49, 943-962.

995 Jarvinen, B. R., C. J. Neumann, and M. A. S. Davis (1984), A tropical cyclone data tape for the North 996 Atlantic Basin, 1886 - 1983: Contents, limitations and uses, Tech. Memo. NWS NHC-22, 21 pp., NOAA, 997 Silver Spring, Md

998 Joyce, R. J., J. E. Janowiak, P. A. Arkin, and P. Xie, (2004), CMORPH: A method that produces global 999 precipitation estimates from passive microwave and infrared data at high spatial and temporal resolution. 1000 J. Hydromet., 5, 487-503.

1001 Klotz, B. W., and E. W. Uhlhorn, (2014), Improved Stepped Frequency Microwave Radiometer Tropical 1002 Cyclone Surface Winds in Heavy Precipitation. J. Atmos. Oceanic Technol., 31, 2392-2408. 1003 doi: http://dx.doi.org/10.1175/JTECH-D-14-00028.1

1004 1005 1006 1007

Knaff, J. A. Mark DeMaria, Debra A. Molenar, Charles R. Sampson, and Matthew G. Seybold, 2011: An Automated, Objective, Multiple-Satellite-Platform Tropical Cyclone Surface Wind Analysis. J. Appl. Meteor. Climatol., 50, 2149-2166. doi: http://dx.doi.org/10.1175/2011JAMC2673.1

Knapp, K. R., M. C. Kruk, D. H. Levinson, H. J. Diamond, and C. J. Neumann, 2010: The International Best Track Archive for Climate Stewardship (IBTrACS): Unifying tropical cyclone best track data. Bulletin of the American Meteorological Society, 91, 363376. doi:10.1175/2009BAMS2755.1

Kudryavtsev, V., P. Golubkin, and B. Chapron (2015), A simplified wave enhancement criterion for moving extreme events, J. Geophys. Res. Oceans, 120, doi:10.1002/2015JC011284.

MacAfee, A. W., and P. J. Bowyer, 2005: The modeling of trapped-fetch waves with tropical cyclonesA desktop operational model. Wea. Forecasting, 20, 245-263.

Meissner, T., and F. J. Wentz (2009), Wind vector retrievals under rain with passive satellite microwave radiometers, IEEE Trans. Geosci. Remote Sens., 47, 3065-3083, doi:10.1109/TGRS.2009.2027012

Molinari, J., and S. Skubis, 1985: Evolution of the surface wind field in an intensifying tropical cyclone. Journal of the Atmospheric Sciences, 42, 2865-2879.

Norberg, W., J. Conaway, D. B. Ross, and T. Wilheit, Measurements of microwave emission from a foam-covered, wind-driven sea, J. Atmos. Sci., 429-435, 1971.

Newell A.C. and V. E. Zakharov, Rough sea foam, Phys. Rev. Lett. 69, 1149, 1992

Powell, M. D., S. H. Houston, L. R. Amat, and N. Morisseau-Leroy (1998), The HRD real-time hurricane wind analysis system, J. Wind Eng. Ind. Aerodyn., 77-78, 53-64, doi:10.1016/S0167-6105(98)00131-7. 
Powell, M.D., 2010: "Near-surface based, airborne, and satellite observations of tropical cyclones." In Global Perspectives on Tropical Cyclones: From Science to Mitigation, J.C.L. Chan and J.D. Kepert (Eds.). World Scientific Publishing Company, 2nd edition, p. 177-199.

Quilfen Yves, Vandemark Doug, Chapron Bertrand, Feng Hui, Sienkiewicz Joe (2011). Estimating Gale to Hurricane Force Winds Using the Satellite Altimeter. Journal of Atmospheric and Oceanic Technology, 28(4), 453-458. http://dx.doi.org/10.1175/JTECH-D-10-05000.1

Rogers, R., and E. Uhlhorn (2008), Observations of the structure and evolution of surface and flight-level wind asymmetries in Hurricane Rita (2005), Geophys. Res. Lett., 35, L22811, doi:10.1029/2008GL034774.

Ruf, C., A. Lyons, M. Unwin, J. Dickinson, R. Rose, D. Rose and M. Vincent, "CYGNSS: Enabling the Future of Hurricane Prediction," IEEE Geosci. Remote Sens. Mag., Vol. 1, No. 2, 52-67, doi: 10.1109/MGRS.2013.2260911, 2013

Reul N. and B.Chapron (2003). A model of sea-foam thickness distribution for passive microwave remote sensing applications. Journal of Geophysical Research Oceans, 108(C10).

Reul \& Ifremer CATDS-CECOS Team 2011, SMOS L3 SSS Research products: Product validation \& Product User Manual Documents Reprocessed Year 2010: IFREMER, Plouzané, France

Reul N., Tenerelli J., Chapron B., Vandemark D., Quilfen Y., and Y. Kerr, "SMOS satellite L-band radiometer: A new capability for ocean surface remote sensing in hurricanes", Journal of Geophysical Research, vol. 117, C02006, doi: 10.1029/2011JC007474, (2012).

Ross, D. B., and V. Cardone, Observations of oceanic whitecaps and their relation to remote measurements of surface wind speed, J. Geophys. Res., 79, 444-452, 1974.

Skou, N., and D. Hoffman-Bang (2005), L-band radiometers measuring salinity from space: Atmospheric propagation effects, IEEE Trans. Geosci. Remote Sens., 43, 2210-2217, doi:10.1109/TGRS.2005.856115.

Uhlhorn, E. W., P. G. Black, J. L. Franklin, M. Goodberlet, J. Carswell, and A. S. Goldstein, 2007: Hurricane surface wind measurements from an operational stepped frequency microwave radiometer. Mon. Wea. Rev., 135, 3070-3085.

Uhlhorn, E. W., B. W. Klotz, T. Vukicevic, P. D. Reasor, and R. F. Rogers, 2014: Observed hurricane wind speed asymmetries and relationships to motion and environmental shear. Mon. Wea. Rev., 142, 1290-1311, doi:10.1175/MWR-D-13-00249.1.

Webster, W. J., T. T. Wilheit, D. B. Ross, and P. Gloersen, Spectral characteristics of the microwave emission from a wind-driven foam covered sea, J. Geophys. Res., 81, 3095-3099, 1976.

Weissman, D.E., Bourassa, M. A. and Tongue, J. (2002) Effects of rain rate and wind magnitude on Sea Winds scatterometer wind speed errors. Journal of Atmospheric and. Oceanic Technology. 19, pp. 738746

Willoughby, H.E., and M. B. Chelmow, 1982, "Objective determination of hurricane tracks from aircraft observations", Mon. Wea. Rev., 110, p.1298-1305. 
1085 Young, I. R. 2003: “A Review of the Sea State Generated by Hurricanes “, Marine Structures. 16, 201218

Yueh, S. H., R.West, W. J. Wislon, F.K. Li, E.G. Njoku, andY. Rahmatsamii (2001), Error sources and feasibility for microwave remote sensing of ocean surface salinity, IEEE Trans. Geosci. Remote Sens., 39, 1049-1060,doi:10.1109/36.921423.

Yueh, S. H., S. J. Dinardo, A. G. Fore, and F. K. Li (2010), Passive and active L-band microwave observations and modeling of ocean surface winds, IEEE Trans. Geosci. Remote Sens., 48(8), 30873100, doi:10.1109/TGRS.2010.2045002.

Zine S, Boutin J, Font J, Reul Nicolas, Waldteufel P, Gabarro C, Tenerelli Joseph, Petitcolin F, Vergely Transactions on geoscience and remote sensing, 46(3), 621-645.

Zabolotskikh E., Mitnik L. M., Reul N. and B. Chapron (2015). New Possibilities for Geophysical Parameter Retrievals Opened by GCOM-W1 AMSR2. IEEE Journal of Selected Topics in Applied Earth Observations and Remote Sensing, PP(99), 1-14. Publisher's official version : http://dx.doi.org/10.1109/JSTARS.2015.241651. 
Fig. 1. Contours of storm-surface induced brightness temperature contrasts $\triangle \mathrm{I}[\mathrm{K}]$ estimated from SMOS L-band data for an ensemble of storms in the Eastern Tropical Pacific (a), Southern Indian Ocean (b), North Atlantic (c), and Western Pacific ocean (d) during 2010-2015. The black thin curves indicate the storm tracks. The coloured contours indicate the amplitude of the storm-induced radio-brightness temperature contrasts $[\mathrm{K}]$.

Fig. 2: Examples of SMOS L-band radio-brightness temperature contrasts $\triangle \mathrm{I}[\mathrm{K}]$ measured for tropical Storms (a,b,c: $35 \leq \mathrm{U}_{10} \leq 63 \mathrm{kts}$ ), category $1 \mathrm{TC}$ (d,e,f: $64 \leq \mathrm{U}_{10} \leq 82 \mathrm{kts}$ ), category $2 \mathrm{TCs}$ (g,h,i: $83 \leq \mathrm{U}_{10} \leq 95 \mathrm{kts}$ ), category 3 TCs (j,k,l; $\left.96 \leq \mathrm{U}_{10} \leq 113 \mathrm{kts}\right)$ and category $4 \mathrm{TCs}\left(\mathrm{m}, \mathrm{n}, \mathrm{o}: 114 \leq \mathrm{U}_{10} \leq 135 \mathrm{kts}\right)$ on the SSWS. Note that the color-scale range is $0-12 \mathrm{~K}$ for TS and category $1,0-15 \mathrm{~K}$ for category 2 to 3 and $0-18 \mathrm{~K}$ for category 4 on the SSWS. Each panel represent a domain of about $1000 \mathrm{~km}$ width centred on the TC eye. The pink dotted curves show the storm 6-hourly best track and the black arrow indicate the storm main propagation direction but not its motion speed.

Fig. 3: (a): SMOS $\Delta \mathrm{I}$ estimated over Category $3 \mathrm{TC}$ Jova at $12: 32 \mathrm{Z}$ on 10 October 2011. The pink dotted curve shows the Best Track of Jova; the white filled dot and squares indicate the eye location estimated by linear interpolation of the Best Track data at SMOS acquisition time and from the closest $85 \mathrm{GHz}$ acquisitions. In this case, the latter is obtained from SSMIS/17 imagery at 12:59 Z (b). (c) and (d) panels: same fields as top panels but provided in a storm-centric frame of $1000 \mathrm{~km}^{2}$ and rotated with respect the storm heading "North Up" that is shown as a white arrow.

Fig. 4. Storm centric contours of the mean (left panels) and standard deviation (right panels) of the L-band radio brightness half power contrast $(\Delta \mathrm{I}[\mathrm{K}])$ as function of storm sector and intensity. The wind intensity is ranging from tropical storms (top panels, $35 \leq \mathrm{U}_{10} \leq 63 \mathrm{kts}$ ), Category $1 \mathrm{TCs}$ (second panels from top, $64 \leq \mathrm{U}_{10} \leq 82 \mathrm{kts}$ ), Category 2 TCs $\left(3^{\text {rd }}\right.$ panels from top, $\left.83 \leq \mathrm{U}_{10} \leq 95 \mathrm{kts}\right)$, Category $3 \mathrm{TCs}\left(4^{\text {th }}\right.$ panels from top, $\left.96 \leq \mathrm{U}_{10} \leq 113 \mathrm{kts}\right)$, Category $4 \mathrm{TCs}\left(5^{\text {th }}\right.$ panels from top, $\left.114 \leq \mathrm{U}_{10} \leq 135 \mathrm{kts}\right)$ and Category 5 (bottom panels, $\left.\mathrm{U}_{10}>135 \mathrm{kts}\right)$. Contours range from 1 to $28 \mathrm{~K}$ in steps of $0.5 \mathrm{~K}$ for the mean and from 0 to $10 \mathrm{~K}$ in steps of $0.2 \mathrm{~K}$ for the standard deviation. Note that the colour scale range is changing from top to bottom panels.

Fig. 5. Mean radial distribution of the storm-induced L-band half-power radio-brightness contrasts $(\triangle I[K])$ as function of storm intensities (colors) given by the Saffir Simpson wind Scale (a) from the South East to the North West storm quadrants and (b) from the South West to the North East storm quadrants.

Fig. 6. (a) Ensemble of SFMR tracks and associated Wind Speed [knots] used for SMOS-SFMR comparisons, and (b) SMOS L-band excess emissivity $(\Delta \mathrm{e})$ contrasts co-located with SFMR flights.

Fig. 7. (a,c,e,g) superimposed SMOS retrieved wind speed using the GMF of Reul et al (2012, color in knots) and SFMR track (black thick curves) for hurricane Daniele the 28 August 2010 (a), hurricane Karl on 16 September 2010 (c); hurricane Earl on 31 August 2010 (e) and hurricane Rina on 25 Oct 2011. The thin dotted curves indicate the storm tracks. b,d,f,h: corresponding time series of the SFMR retrieved wind speed in $\mathrm{m} / \mathrm{s}$ (black curve) and rain rate in $\mathrm{mm} / \mathrm{h}$ (grey curve) at nominal resolution along aircraft track $(\sim 3 \mathrm{~km})$. The SFMR retrieved wind speed has been spatially averaged with a running window of $43 \mathrm{~km}$ width along track (corresponding to the mean resolution of SMOS interferometer pixels) is shown in blue. The retrieved wind speed from SMOS is shown in red using GMF1 and in magenta using GMF2. The $\mathrm{x}$-axis shows the time lag between SFMR acquisitions and SMOS ones.

Fig. 8: SMOS storm-induced excess L-band emissivity, $\triangle \mathrm{e}$, as function of co-located SFMR wind speed for an ensemble of 64 SMFR flights in the Gulf of Mexico and western Atlantic ocean. The time lags between both observations never exceed $6 \mathrm{~h}$. The red line indicate the first bi-linear GMF proposed in Reul et al. (2012). The cyan curve indicates the mean wind-excess emissivity per $10 \mathrm{kt}$-width bins and the vertical bars indicate \pm 1 standard deviation of the emissivity within each bin. 
Fig. 9. (a) Surface wind speed retrieved from SMOS (GMF of Reul et al (2012)) in a storm centric coordinate system for hurricane Leslie on 7th September 2012 at 22:19. (b) $\mathrm{H}^{*}$ WIND fields interpolated at SMOS acquistion time and spatially averaged at $43 \mathrm{~km}$ resolution. (c) Mean radial distribution of the SMOS (black) and $\mathrm{H}^{*}$ WIND (blue) surface wind speed from the SW to the NE storm quadrants, and (d) from the NW to the SE storm quadrants. (e) CMORPH rain rate at SMOS acquisition time. (f) SMOS retrieved wind speed as function of $\mathrm{H}^{*}$ WIND with color indicating the rain rate from CMORPH.

Fig. 10. Same caption as Fig.9 except for the case of hurricane Katia on the $6^{\text {th }}$ September 2011 at 09:35 Z.

Fig. 11: Wind Excess emissivity $\triangle \mathrm{e}$ as function of co-located $\mathrm{H}^{*}$ WIND wind speed for an ensemble of storms in between 2010 and 2013. The red curve illustrates the SMOS GMF of Reul et al (2012). The cyan curve show the new 'average' GMF function derived in this paper based on the SMOS and H*WIND paired data. $\triangle \mathrm{e}$ data have been averaged into bins of $\mathrm{H}^{*} \mathrm{WIND}$ winds at 5 knots intervals with the vertical error bar indicating \pm 1 standard deviation of the $\Delta \mathrm{e}$ within each wind speed bin.

1207

1208

Fig. 12: Potential effects of rain on the excess L-band emissivity $\triangle \mathrm{e}$ in storm conditions. Top: GMF deduced from the SMOS and $\mathrm{H}^{*}$ WIND matchups with rain rate provided from CMORPH=0 (red) and rain rate $>0$ (blue). Bottom: similar caption than for the top plot except that the data are now classified by ranges of rain rate (RR): $R R=0$ (red), $0<R R \leq 5 \mathrm{~mm} / \mathrm{h}$ (green), $5 \mathrm{~mm} / \mathrm{h}<\mathrm{RR}<\leq 10 \mathrm{~mm} / \mathrm{h}$ (cyan) and $\mathrm{RR}>10 \mathrm{~mm} / \mathrm{h}$. (blue).

Fig. 13: (a) Comparisons between co-located SMOS retrievals (GMF1) and H*WIND surface winds for an ensemble of $\sim 30$ tropical storms and hurricanes over the period 2010-2013 (b) Histogram of the differences between co-located SMOS and $\mathrm{H}^{*}$ WIND surface winds. The orange curve is a Gaussian fit with standard deviation of $8.3 \mathrm{kt}$. (c) $\mathrm{H}^{*}$ WIND versus ECMWF winds and (d) NCEP winds versus $\mathrm{H}^{*}$ WIND. The gray curves are showing the mean $\mathrm{y}$-axis wind speed in bins of $2 \mathrm{kt}$ width of $\mathrm{H}^{*} \mathrm{WIND}$ surface wind speed data \pm 1 standard deviation. Root mean square differences (RMSD) and biases between each products and $\mathrm{H}^{*}$ WIND ones are provided in table 1 .

Fig 14: Relationships between the maximum of SMOS winds as function of the Best track Maximum Sustained Wind speed.

Fig. 15. Synoptic structure of the surface wind field in Tropical Cyclones as retrieved from SMOS data as function of the Saffir-Simpson High Wind intensity scale. Average 2D wind fields from SMOS are contoured at levels of 34 (thick dark blue), 44 (thin blue), 50 (thick cyan), 64 (thick red), 80 (gray) and 94 (thick chesnut) kt. The thick black arrow is indicating the averaged storm propagation direction. 